\title{
Simultaneously Excitatory and Inhibitory Effects of Transcranial Alternating Current Stimulation Revealed Using Selective Pulse-Train Stimulation in the Rat Motor Cortex
}

\author{
Ahmad Khatoun, Boateng Asamoah, and Myles Mc Laughlin \\ Research Group Experimental ORL, Department of Neurosciences, KU Leuven, 3000 Leuven, Belgium
}

Transcranial alternating current stimulation (tACS) uses sinusoidal, subthreshold, electric fields to modulate cortical processing. Cortical processing depends on a fine balance between excitation and inhibition and tACS acts on both excitatory and inhibitory cortical neurons. Given this, it is not clear whether tACS should increase or decrease cortical excitability. We investigated this using transcranial current stimulation of the rat (all males) motor cortex consisting of a continuous subthreshold sine wave with short bursts of suprathreshold pulse-trains inserted at different phases to probe cortical excitability. We found that when a low-rate, long-duration, suprathreshold pulse-train was used, subthreshold cathodal tACS decreased cortical excitability and anodal tACS increased excitability. However, when a high-rate, short-duration, suprathreshold pulse-train was used this pattern was inverted. An integrate-and-fire model incorporating biophysical differences between cortical excitatory and inhibitory neurons could predict the experimental data and helped interpret these results. The model indicated that low-rate suprathreshold pulse-trains preferentially stimulate excitatory cortical neurons, whereas high-rate suprathreshold pulse-trains stimulate both excitatory and inhibitory neurons. If correct, this indicates that suprathreshold pulse-train stimulation may be able to selectively control the excitation-inhibition balance within a cortical network. The excitationinhibition balance then likely plays an important role in determining whether subthreshold tACS will increase or decrease cortical excitability.

Key words: direct cortical stimulation; neuromodulation; transcranial alternating current stimulation; transcranial magnetic stimulation

Significance Statement

Transcranial alternating current stimulation (tACS) is a noninvasive neuromodulation method that uses weak sinusoidal electric fields to modulate cortical activity. In healthy volunteers tACS can modulate perception, cognition, and motor function but the underlying neural mechanism is poorly understood. In this study, using rat motor cortex, we found that tACS effects are highly variable: applying the same tACS waveform to the same cortical area does not always give the same change in cortical excitability. An integrate-and-fire model incorporating excitatory pyramidal and inhibitory interneurons indicated that tACS effects likely depend on the cortical excitation-inhibition balance. When cortical activity is excitation dominated one particular tACS phase increases excitability, but when the cortical activity is inhibition dominated the same tACS phase actually decreases excitability.

\section{Introduction}

Transcranial alternating current stimulation (tACS) is a noninvasive neuromodulation method in which a weak electric field

Received May 22, 2017; revised Aug. 3, 2017; accepted Aug. 10, 2017.

Author contributions: M.M.L. designed research; A.K. and M.M.L. performed research; A.K., B.A., and M.M.L. analyzed data; A.K., B.A., and M.M.L. wrote the paper.

This work was supported by Research Fund KU Leuven (STG/14/024).

The authors declare no competing financial interests.

Correspondence should be addressed to Myles Mc Laughlin, Research Group Experimental Oto-rhino-

laryngology, 0\&N II Herestraat 49, Box 721, 3000 Leuven, Belgium. E-mail: myles.mclaughlin@kuleuven.be. modulates cortical neural activity (Reato et al., 2010; Antal and Paulus, 2013). tACS differs from other neuromodulation methods, such as direct cortical stimulation (Nguyen et al., 1999; Priori and Lefaucheur, 2007) or transcranial magnetic stimulation (TMS; Pashut et al., 2011), that use strong, pulsed fields to initiate action potentials. Instead, tACS uses a sinusoidal alternating electric field that is too weak to directly initiate action potentials. The 
Transcranial current stimulation waveform

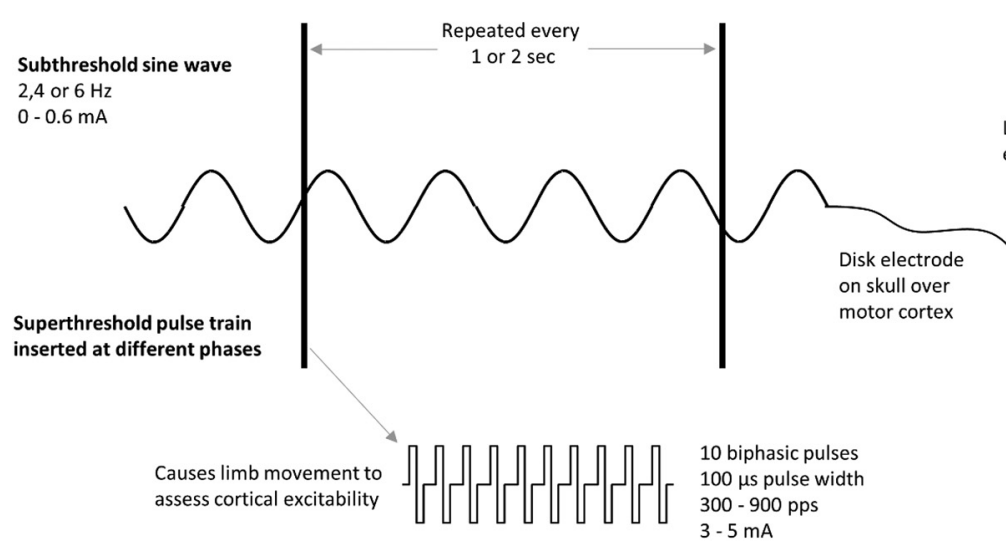

Anesthetized rat preparation Outcome measurement

Figure 1. Schematic diagram of the rat experimental setup and the combined subthreshold and suprathreshold transcranial current stimulation paradigm. In an anesthetized rat the skull was exposed and a small disk electrode was placed over the motor cortex hindlimb area and a large return electrode was placed a few millimeters posterior to it. An accelerometer was placed on the hindlimb contralateral to the stimulating electrode to quantify stimulation-induced limb movement. Transcranial current stimulation consisted of a continuous subthreshold sine wave (i.e., not strong enough to cause a limb movement) with a short suprathreshold pulse-train inserted at different phases of the sine wave to induce limb movement and assess cortical excitability. The output of the accelerometer to one suprathreshold pulse-train at a particular subthreshold tACS phase is shown on the far left.

precise details of how tACS interacts with ongoing cortical activity are not fully understood, but tACS can cause small membrane potential modulations (Deans et al., 2007) which may entrain neural activity across a large network (Fröhlich and McCormick, 2010). We know that cortical processing depends on a fine balance between excitation and inhibition (Galarreta and Hestrin, 1998; Chen, 2004; Buzsáki, 2006; Krause et al., 2013) and that weak electric fields modulate the membrane potential of both excitatory and inhibitory neurons (Radman et al., 2009). With this in mind, one may expect the effect of tACS on cortical activity to be complex and to be influenced by the ongoing cortical excitation-inhibition balance.

Cortical excitatory pyramidal (PyE) neurons and inhibitory interneurons have important biophysical differences. PyE neurons have a large apical dendritic tree, whereas the dendrites of inhibitory interneurons branch out in all directions (Soediono, 1989; DeFelipe and Fariñas, 1992). Subthreshold electric fields polarize the membrane of both neuron types (Radman et al., 2009), but polarization is stronger in PyE (Tranchina and Nicholson, 1986). Another important biophysical distinction is the membrane time constant: fast-spiking inhibitory interneurons (FSIs) have a short time constant, whereas PyE neurons have a longer time constant (Thomson, 1997; Gibson et al., 1999; Ascoli et al., 2008; Kelsom and Lu, 2013). Suprathreshold pulse-train stimulation initiates action potentials in axons which sustain high firing rates (Nowak and Bullier, 1998; McIntyre et al., 2004). These electrically initiated action potentials modulate cortical activity via direct and indirect routes (Di Lazzaro et al., 2008): some axons project out of the cortex directly delivering stimulation effects downstream, whereas others project within the cortex to PyE neurons and FSIs causing indirect presynaptic stimulation (Hussin et al., 2015). With the indirect route the membrane time constant plays an important role in determining whether a postsynaptic neuron will fire an action potential (König et al., 1996; Tal and Schwartz, 1997).

Low-frequency tACS changes cortical excitability in a phasic way with one phase increasing excitability and the opposite phase decreasing it (Ozen et al., 2010; Ali et al., 2013; Brittain et al., 2013; Guerra et al., 2016; Raco et al., 2016). However, given that cortical processing depends on a balance between excitatory and inhibitory neurons and that weak electric fields polarize both neuron types, it is not clear which phase should increase excitability and which should decreases excitability. We reasoned that the effect of low-frequency tACS on cortical excitability should depend on the excitation-inhibition balance: when excitatory activity is dominant one particular tACS phase should increase excitability, but when inhibitory activity is dominant the same tACS phase should decrease excitability.

We investigated this using transcranial current stimulation of the rat motor cortex. We delivered continuous, subthreshold, sine wave stimulation (tACS) and inserted bursts of suprathreshold pulse-train stimuli at different phases to probe excitability. Results showed that with a low-rate, long-duration, suprathreshold pulse-train, cathodic tACS decreased excitability, whereas anodic tACS increased excitability. However, with a high-rate, short-duration, pulse-train the tACS effect was inverted. An integrate-and-fire model where the FSIs had a faster membrane time constant than PyE neurons accounted for the observed results. The model indicated that longer low-rate, suprathreshold pulse-trains may preferential stimulate $\mathrm{PyE}$ neurons, whereas shorter high-rate pulse-trains stimulate both PyE neurons and FSIs. Furthermore, the model indicated that changing pulse-train parameters may provide a mechanism to control the excitationinhibition balance and that this balance determined whether tACS increased or decreased cortical excitability.

\section{Materials and Methods}

Animals. Twelve male Wistar rats $(514 \pm 108 \mathrm{~g})$ were used in the experiment. Rats were housed in pairs with food and water available ad libitum. Animals were maintained on a 14/10 h light/dark cycle (lights on at 7:00 A.M.), with a room temperature of $\sim 19^{\circ} \mathrm{C}$. The protocol was approved by the KU Leuven ethics committee for laboratory experimentation (project P096/2015).

Surgery. Rats were anesthetized with a mixture of ketamine $(45 \mathrm{mg} / \mathrm{kg}$ i.p., Anesketin, Eurovet) and medetomidine $\mathrm{HCl}$ ( $0.3 \mathrm{mg} / \mathrm{kg}$ i.p., Narcostart, Kela Veterinaria). Disk electrodes, placed on the skull, were used to deliver transcranial current stimulation. First, the skull was exposed by making an incision in the skin. Then one small-diameter $(4 \mathrm{~mm})$ disk electrode was placed over the right motor cortex hindlimb area (coordinates with respect to bregma: $\mathrm{AP}=0.5 \mathrm{~mm}, \mathrm{ML}=2.5 \mathrm{~mm}$ ) and a large disk electrode ( $9 \mathrm{~mm}$ diameter) was placed on the midline $9.5 \mathrm{~mm}$ pos- 
terior to bregma which served as the return electrode (Fig. 1). A thin layer of conductive gel (Signagel, Parker Laboratories) was placed under the electrodes to ensure good electrical contact with the skull. If electrical stimulation did not cause hindlimb movement the position of the small electrode was adjusted until a satisfactory selective movement was observed. The level of anesthesia was monitored by checking the toe-pinch reflex and controlled via an intraperitoneal perfusion of ketamine (13.33 $\mathrm{mg} / \mathrm{ml}$ ). During surgery a deep level of anesthesia was maintained (no reflex to toe-pinch), whereas during the stimulation experiment a light level of anesthesia was maintained (clear toe-pinch reflex). This corresponded to a flow rate of $\sim 0.5 \mathrm{ml} / \mathrm{h}$ in most animals.

Limb movement measurements. To monitor limb movement a triaxial accelerometer (ADXL353, Analog Devices) was attached to the hindlimb contralateral to the stimulation site. The three axis were digitized (NI USB-6216, National Instruments) at $20 \mathrm{kHz}$ sample rate, displayed online, and recorded for off-line analysis using custom written MATLAB software (MathWorks).

Electrical stimulation. Electrical stimulation was delivered using a DS5 current source (Digitimer) controlled by an analog voltage waveform input. The voltage waveform was generated using an output channel on a data acquisition card (NI USB-6216, National Instruments) and controlled via custom written MATLAB software (MathWorks) at a sample rate of $20 \mathrm{kHz}$

Using this setup, two types of stimulation could be delivered through the same disk electrodes: subthreshold sine waves (similar to conventional tACS and referred to here as subthreshold tACS) and suprathreshold pulsetrains (Fig. 1). The subthreshold and suprathreshold distinction refers to induction of limb movement. Subthreshold tACS sine waves were applied at low current amplitudes $(0,0.05,0.1,0.2,0.3,0.4,0.5$, and $0.6 \mathrm{~mA})$ and low frequencies $(2,4$, and $6 \mathrm{~Hz})$ and did not cause limb movements. While suprathreshold biphasic (200 $\mu$ s per phase) rectangular pulse trains were applied at higher amplitudes (2.7-4.5 mA) and did cause limb movement, the suprathreshold pulse-trains were short (11-33 ms), containing only 10 pulses with rates of either $300,400,500,600,700,800$, or 900 pulse per second (pps). Importantly, because each pulse train had the same number of pulses, it injected exactly the same amount of charge into the system. This design allowed us to examine the effect of pulsetrain rate while keeping the pulse amplitude and total amount of charge constant. Subthreshold tACS was applied continuously, whereas suprathreshold pulse-trains were systematically inserted at different subthreshold tACS phases to cause a limb movement which was measured via the accelerometer. Importantly, the duration of the suprathreshold pulse-trains was always significantly shorter than the tACS period. Suprathreshold pulse-trains were spaced either $1,1.5$, or $2 \mathrm{~s}$ apart. This timing between suprathreshold pulses-trains was approximate because it needs to be slightly adjusted to coincide exactly with a particular tACS phase. Importantly, when a suprathreshold pulse-train was inserted the tACS waveform was effectively switched off during each individual pulse but back on during the gap between each pulse. This ensured (1) that suprathreshold pulse-trains delivered at different tACS phases had the same amplitude and (2) that the tACS sine wave was only minimally disturbed. For a range of tACS phases ( $0-1$ cycle, in steps of 0.125 cycles) data from 15 limb responses per phase were collected in a randomized order to yield one phase- limb response function. In the 12 rats different combinations of subthreshold tACS frequencies $(2,4$, or $6 \mathrm{~Hz})$ and suprathreshold pulse-train rates $(300-900 \mathrm{pps})$ were collected to cover a range of combinations, but every combination was not collected in every rat. For each different combinations of tACS frequencies and pulse-train rates data were collected using a range of tACS amplitudes $(0-0.6 \mathrm{~mA})$. The full data sampling is reported in Table 1 and consists of a total of 168 phase-limb response functions across all 12 animals.

Quantification of cortical excitability. Cortical excitability was quantified based on hindlimb accelerometer data. The raw acceleration data were bandpass filtered between 1 and $500 \mathrm{~Hz}$ (second-order Butterworth) and integrated twice to give the limb displacement in arbitrary units. Principal component analysis was used to combine the three displacement axis and limb displacement defined as the first principal component. The difference between the minimum and maximum limb
Table 1. A complete overview of all the combinations of suprathreshold pulse-train rate, subthreshold tACS frequency, and amplitude tested in each rat

\begin{tabular}{|c|c|c|c|}
\hline Rat & Pulse-train rate, pps & tACS freq, $\mathrm{Hz}$ & tACS amplitude, $\mathrm{mA}$ \\
\hline \multirow[t]{3}{*}{1} & 300 & 2 & $0.6,0.4,0.2$ \\
\hline & 300 & 4 & $0.6,0.4,0.2$ \\
\hline & 300 & 6 & $0.6,0.4,0.2$ \\
\hline \multirow[t]{2}{*}{2} & 300 & 4 & 0.6 \\
\hline & 500 & 4 & $0.6,0.4,0.2,0.1,0.05$ \\
\hline \multirow[t]{2}{*}{3} & 300 & 4 & $0.6,0.4,0.3$ \\
\hline & 500 & 4 & 0.6 \\
\hline \multirow[t]{2}{*}{4} & 300 & 4 & $0.6,0.5,0.4,0.3,0.2,0.1,0$ \\
\hline & 500 & 4 & $0.6,0.5,0.4,0.3,0.2,0.1,0$ \\
\hline \multirow[t]{6}{*}{5} & 300 & 2 & $0.6,0.4,0.2,0$ \\
\hline & 300 & 4 & $0.6,0.4,0.2,0$ \\
\hline & 300 & 6 & 0.6 \\
\hline & 500 & 2 & $0.6,0.4,0.2,0.1,0.05,0$ \\
\hline & 500 & 4 & $0.6,0.4,0.2,0$ \\
\hline & 500 & 6 & 0.6 \\
\hline \multirow[t]{6}{*}{6} & 300 & 2 & $0.6,0.4,0$ \\
\hline & 300 & 4 & $0.6,0.4,0$ \\
\hline & 300 & 6 & $0.6,0$ \\
\hline & 500 & 2 & $0.6,0.4,0$ \\
\hline & 500 & 4 & $0.6,0.4,0$ \\
\hline & 500 & 6 & $0.6,0$ \\
\hline \multirow[t]{4}{*}{7} & 300 & 2 & $0.6,0.4,0$ \\
\hline & 300 & 4 & $0.6,0.4,0.2,0$ \\
\hline & 500 & 2 & $0.6,0.4,0$ \\
\hline & 500 & 4 & $0.6,0.4,0.2,0$ \\
\hline \multirow[t]{11}{*}{8} & 300 & 2 & $0.6,0.4,0.2,0$ \\
\hline & 300 & 4 & $0.6,0.4,0.2,0.1,0$ \\
\hline & 300 & 6 & $0.6,0.4,0.2,0.1,0.05,0$ \\
\hline & 400 & 4 & 0.4 \\
\hline & 500 & 4 & 0.4 \\
\hline & 600 & 2 & $0.6,0.4,0.2,0$ \\
\hline & 600 & 4 & $0.6,0.4,0.2,0.1,0$ \\
\hline & 600 & 6 & $0.6,0.4,0.2,0.1,0$ \\
\hline & 700 & 4 & 0.4 \\
\hline & 800 & 2 & $0.6,0.4,0.2,0.1,0.05,0$ \\
\hline & 800 & 4 & 0.4 \\
\hline \multirow[t]{2}{*}{9} & 300 & 4 & $0.6,0.4$ \\
\hline & 600 & 4 & 0.6 \\
\hline \multirow[t]{12}{*}{10} & 300 & 2 & 0.6 \\
\hline & 300 & 4 & $0.6,0.4,0.2,0$ \\
\hline & 300 & 6 & $0.6,0.4,0.2,0.1,0$ \\
\hline & 500 & 4 & 0.4 \\
\hline & 500 & 6 & 0.4 \\
\hline & 600 & 6 & 0.4 \\
\hline & 700 & 2 & 0.6 \\
\hline & 700 & 4 & 0.4 \\
\hline & 800 & 6 & $0.6,0.4,0.2,0.1,0$ \\
\hline & 900 & 2 & 0.6 \\
\hline & 900 & 4 & $0.6,0.4,0.2,0$ \\
\hline & 900 & 6 & 0.4 \\
\hline \multirow[t]{4}{*}{11} & 300 & 2 & $0.6,0.4,0.2,0$ \\
\hline & 300 & 4 & $0.4,0$ \\
\hline & 900 & 2 & 0.2 \\
\hline & 900 & 4 & $0.4,0$ \\
\hline \multirow[t]{6}{*}{12} & 300 & 2 & $0.4,0.2$ \\
\hline & 300 & 4 & 0.4 \\
\hline & 500 & 4 & 0.2 \\
\hline & 700 & 2 & $0.4,0.2$ \\
\hline & 700 & 4 & 0.4 \\
\hline & 900 & 4 & 0.2 \\
\hline
\end{tabular}

displacement occurring after stimulation was then calculated to give limb displacement amplitude for each stimulus repetition.

The mean and the $95 \%$ confidence intervals of the 15 limb displacement amplitudes at each subthreshold tACS phase were calculated 
A

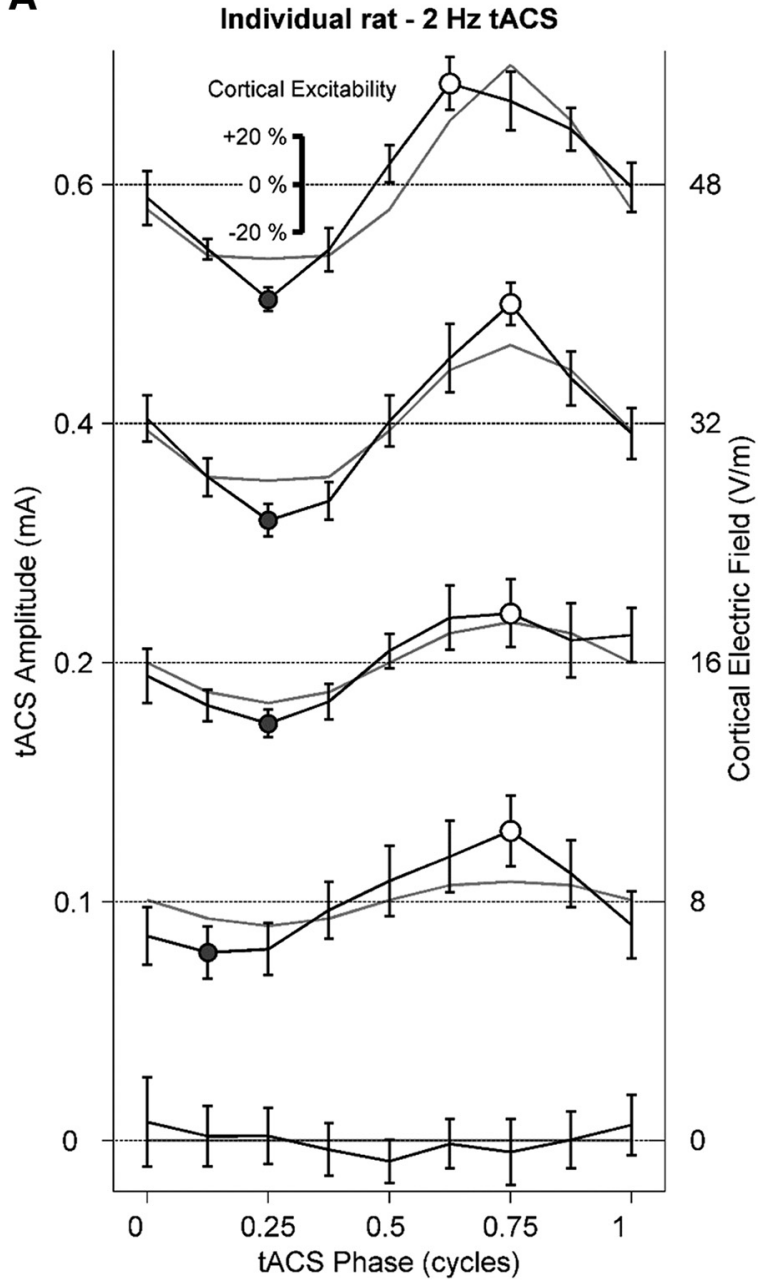

B

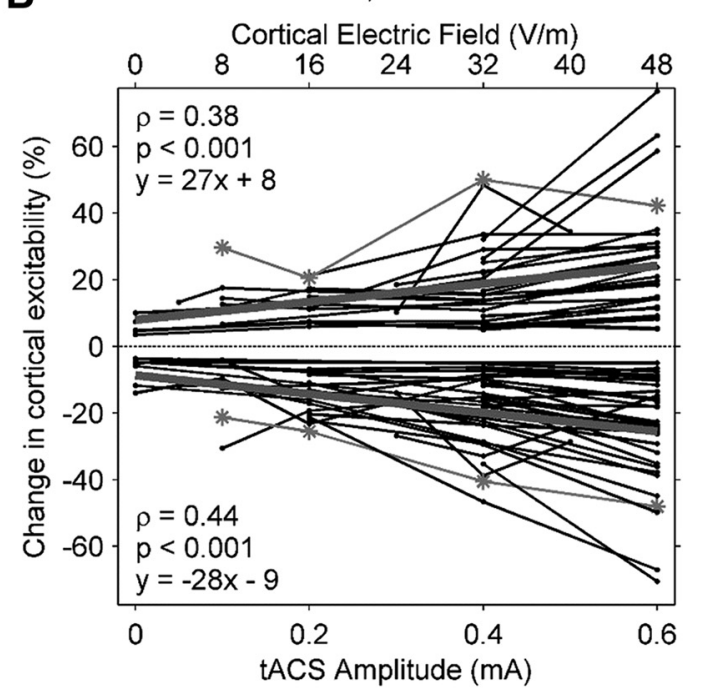

Figure 2. Results illustrating the effects of the subthreshold tACS phase and amplitude on the cortical excitability. $A$, The change in cortical excitability as a function of the subthreshold tACS phase is shown for a range of the subthreshold tACS amplitudes $(0-0.6 \mathrm{~mA}$, black lines with error bars) for one rat. Note, the suprathreshold pulse-train amplitude was held constant ( $2.7 \mathrm{~mA}$ ) for all subthreshold tACS amplitudes tested. When no subthreshold tACS was applied $(0 \mathrm{~mA})$, no significant changes in excitability were detected. Progressively increasing subthreshold tACS amplitude (0.1-0.6 mA), produced an increase in cortical excitability at one phase and a decrease in cortical excitably at an opposite phase. Error bars show $95 \%$ confidence
(Fig. 2A, black line shows mean limb displacement and error bars show 95\% confidence intervals). These data were then used to determine whether there was a significant increase or decrease in cortical excitability for each phase. First a grand average of all limb displacement amplitudes, across all phases, was calculated (Fig. 2A, dotted line). Mean limb displacement at one phase was then calculated as a percentage change from the grand average and used to define cortical excitability (Fig. $2 A$, inset scale). This procedure yielded a phase-cortical excitability function (Fig. 2A). If the 95\% confidence intervals for one mean limb displacement at a particular phase did not overlap with the grand average it was considered significant.

An alternative to using the grand average across all phases to define baseline cortical excitability would be to use data collected at $0 \mathrm{~mA}$ tACS amplitude. However, as shown in Table 1 these data were not available for all tACS frequencies and suprathreshold pulse-train rate combinations. For the data where $0 \mathrm{~mA}$ tACS amplitudes were available cortical excitability was calculated using both approaches and found to differ by an average of $4.1 \pm 2.5 \%$ change in cortical excitability across all maxima and minima. All data reported here use the grand mean baseline.

Sine wave fitting procedure. To further quantify and parameterize the phase-cortical excitability functions we fitted them with a sine wave function consisting of two free parameters describing the sine wave amplitude and phase. Here, the fitted amplitude value gives an indication of the maximum increase and decrease in cortical excitability, whereas the fitted phase values indicates whether the cathodal tACS phase caused an increase or decrease in cortical excitability (a fitted phase of 0 cycles means cathodic tACS increases cortical excitability, whereas 0.5 cycles means that cathodic tACS decreases cortical excitability). The fitting procedure was performed in MATLAB using the lsqcurvefit function.

Statistics. A two-way ANOVA was used to examine whether tACS phase and tACS amplitude had an effect on cortical excitability. Paired $t$ tests where used to compare the effect of a low- or high-rate pulse train on the tACS phases at which maximum increase or decrease in cortical excitability occurred. MATLAB (MathWorks) was used for all statistics and significance was set at $p<0.05$.

Leaky integrate-and-fire neuron population model. To gain a better understanding of the possible neural mechanisms underlying the results from the rat experiments we modeled a population of 100 PyE neurons and 100 FSIs. We suspected that some of the observed experimental results could be accounted for by differences in the membrane time constants of PyE neurons and FSIs, leading to different amounts of temporal integration of the suprathreshold pulse-train stimuli. Therefore, we selected a leaky integrate-and-fire model because this class of model can readily capture temporal integration differences without the need for the complexity of a full biophysical model. A leaky integrate-and-fire model (Stein, 1967; Gerstner and Kistler, 2002) was used to describe each neuron in the population:

$$
\tau \frac{d V}{d t}=-\left(V(t)-E_{L}\right)+I(t) R
$$

where $V$ is the membrane potential, $E_{L}$ is the equilibrium potential, $I$ is the synaptic current and $R$ is the membrane resistance such that $R$ mul-

$\leftarrow$

intervals for 15 repetitions at one phase and straight dotted line shows grand mean of the cortical excitability across all phases at that specific tACS amplitude. A phase was defined as producing a significant change in cortical excitability if the $95 \%$ confident interval did not overlap with the grand mean. The maximum increase/decrease in cortical excitability for each tACS amplitude tested is indicated with a white/black dot. The $y$-axis on the right side shows the corresponding cortical electric field strength estimated from the electro-anatomical model (Fig. 8). The light gray lines show the changes in cortical excitability predicted by the integrate-andfire model for these specific stimulation parameters. $\boldsymbol{B}$, The maximum significant increase and decrease in cortical excitability as a function of the subthreshold tACS amplitude is shown for al datasets for all rats. In general, the results show a linear, monotonic, relation between the subthreshold tACS amplitude and changes in cortical excitability. The dark gray line shows a linear regression fit to the data. There is a significant $(p<0.001)$ correlation between tACS amplitude and cortical excitability. The light gray line with stars highlights the dataset from $\boldsymbol{A}$. 
Table 2. Integrate-and-fire model parameters for PyE neurons and FSIs

\begin{tabular}{|c|c|c|}
\hline & PyE & $\mathrm{FSI}$ \\
\hline$\tau, \mathrm{ms}$ & 18 & 9 \\
\hline$R, M \Omega$ & 36 & 18 \\
\hline$C, \mathrm{nF}$ & 0.5 & 0.5 \\
\hline$V_{\text {init }}, m V$ & $-57.5 \pm 2.5$ & $-57.5 \pm 2.5$ \\
\hline$E_{\mathrm{L}}, \mathrm{mV}$ & -60 & -60 \\
\hline$V_{\text {thr }}, \mathrm{mV}$ & -40 & -40 \\
\hline$V_{r}, \mathrm{mV}$ & -50 & -50 \\
\hline$\Delta_{\text {abs }}, \mathrm{ms}$ & 10 & 3 \\
\hline$g_{\mathrm{a}}, \mathrm{nS}$ & $0.018 \pm 0.009$ & $0.0513 \pm 0.0256$ \\
\hline$t_{\text {peak }}, \mathrm{ms}$ & 1.2 & 0.4 \\
\hline$E_{\text {syn }} E x, m V$ & 0 & 0 \\
\hline$E_{\text {syn }} \ln , \mathrm{mV}$ & -75 & $\mathrm{n} / \mathrm{a}$ \\
\hline$\lambda, \mathrm{mm}$ & 0.2 & 0.1 \\
\hline
\end{tabular}

$\tau$, Membrane time constant; $R$, membrane resistance; $C$, membrane capacitance; $V_{\text {init }}$, initiation potential; $E_{L}$ equilibrium potential; $V_{t \text { thr }}$, threshold potential; $V_{r}$, reset potential; $\Delta_{\text {abs }}$, absolute refractory period; $g_{a}$, peak synaptic conductance; $t_{\text {peak }}$, time to peak conductance; $E_{\text {syn }}$ Ex, excitatory synaptic reversal potential; $E_{\text {syn }}$ In, inhibitory synaptic reversal potential; $\lambda$, polarization length constant.

tiplied by the membrane capacitance $(C)$ defines the membrane time constant $\tau$. A spike being fired at time $t^{(f)}$ was defined by the membrane potential reaching a threshold potential $\left(V_{\text {thr }}\right)$, such that:

$$
t^{(f)}: V\left(t^{(f)}\right)=V_{t h r} .
$$

Following a spike, a refractory period $\left(\Delta_{\text {abs }}\right)$ was imposed during which the membrane potential was held at the reset potential $\left(V_{\mathrm{r}}\right)$. The time course of current due to one synaptic input $(\alpha(t))$ was described using an $\alpha$ function of the form:

$$
\begin{gathered}
\alpha\left(t-t^{(f)}\right)=g\left(t-t^{(f)}\right)\left[V(t)-E_{s y n}\right] \\
g(s)=\frac{g_{a}}{t_{\text {peak }} \exp (-1)} s \exp \left(-s / t_{\text {peak }}\right),
\end{gathered}
$$

where $g(s)$ describes the time course of the change in the membrane conductance due to one synaptic input, $g_{a}$ defines the peak synaptic conductance, $t_{\text {peak }}$ is the time at which $g_{a}$ is reached and $E_{\text {syn }}$ is the reversal potential of the synapse. For presynaptic neurons $j$ firing spikes at time $t_{j}^{(f)}$ the total synaptic current $(I)$ input to a postsynaptic neuron $i$ was defined as follows:

$$
I_{i}(t)=\sum_{j} w \sum_{f} \alpha\left(t-t_{j}^{(f)}\right),
$$

where $w$ describes the synaptic efficiency. A population of 100 PyE neurons and 100 FSIs were modeled using the parameters from the first and second columns, respectively, in Table 2. PyE neurons are known to receive $\sim 10$ inhibitory synapses from FSIs, whereas PyE neurons give only a few excitatory synapses onto FSIs (Wang et al., 2002; Markram et al., 2004; Gupta et al., 2007). We adopted a parsimonious approach and set model synaptic connections such that one PyE neuron received inhibitory input from 10 randomly selected FSIs, whereas PyE neurons did not give any excitatory synapses onto FSIs. Because the population only includes one type of synaptic connection (i.e., inhibition from FSI to $\mathrm{PyE})$ a single value for $w$ was sufficient.

Our hypothesis was that the observed rat experimental results could be explained by biophysical differences in PyE neurons and FSIs which become apparent when these neurons are presynaptically stimulated with suprathreshold pulse-trains of differing pulse-rates. In our parsimonious approach we only modeled the indirect suprathreshold stimulation route; i.e., action potentials are initiated in axons which project to both PyE neurons and FSIs. In the direct route, action potentials are initiated in $\mathrm{PyE}$ axons projecting out of the cortex. Action potentials for the direct route would be less affected by biophysical differences between PyE neurons and FSIs and were therefore not included in the integrate-and-fire model.

Suprathreshold pulse-train stimulation was simulated by generating one excitatory synaptic input for all model neurons (both PyE and FSI) for each pulse in the pulse-train, i.e., one $\alpha$ function with amplitude $g_{a}$. A very low-amplitude pulse-train would theoretically stimulate just one axon. In our model this would result in one EPSP for each pulse in the pulse-train in all PyE and FSI model neurons. As the amplitude of the pulse-train is increased more axons will be stimulated meaning that one pulse will result in a number of synchronous EPSPs (we refer to this as a compound EPSP). In the model we simulated an increase in suprathreshold amplitude as an increase in $g_{a}$, resulting in a larger EPSP. Thus, $g_{a}$ represents a compound synaptic conductance caused by multiple, synchronous, presynaptic inputs and results in one compound EPSP.

The main difference between the model PyE neurons and FSIs is the membrane time constant. Based on typical values from the literature, $\tau$ was set to $18 \mathrm{~ms}$ in PyE neurons and $9 \mathrm{~ms}$ in FSIs (Connors and Gutnick, 1990; Kawaguchi, 1993, 1995; Thomson, 1997; Beierlein et al., 2003; Compte et al., 2003; Povysheva et al., 2006). EPSPs in FSIs have a faster rise time than in PyE neurons, accordingly $t_{\text {peak }}$ was set to $0.4 \mathrm{~ms}$ for FSIs and $1.2 \mathrm{~ms}$ for PyE neurons. IPSPs in PyE neurons caused by input from FSIs are known to have a longer duration than EPSPs (Beierlein et al., 2003). Therefore, $t_{\text {peak }}$ for the inhibitory input to PyE neurons was set to $2 \mathrm{~ms}$ and the synaptic conductance value $g_{a}$ for an inhibitory input to a PyE neuron was equal but opposite to that of an excitatory input. The weight of this inhibitory synaptic input could be further controlled by changing the synaptic efficiency parameter $w$ and its value is described further in Results. FSIs can fire at much higher rates than PyE neurons (Beierlein et al., 2003). Therefore, PyE neurons were assigned $\Delta_{\text {abs }}$ of 10 ms limiting their maximum firing rate to $100 \mathrm{~Hz}$, whereas FSIs were assigned $\Delta_{\mathrm{abs}}$ of $3 \mathrm{~ms}$ limiting their maximum firing rate to $333 \mathrm{~Hz}$. Each PyE neuron and FSI was assigned a different initial membrane potential $\left(V_{\text {init }}\right)$ drawn from a normal distribution with a mean of $-57.5 \mathrm{mV}$ and $\mathrm{SD}$ of $2.5 \mathrm{mV}$. Synaptic conductance values for each neuron were always drawn from a normal distribution and with SD equal to half its mean. The mean of the synaptic conductance distribution could then be varied to simulate the effect of stronger or weak suprathreshold pulse-train stimulation.

Subthreshold tACS for any given phase was simulated as static shift in the initial membrane potential $\left(V_{\text {init }}\right)$ and in the reset potential $\left(V_{\mathrm{r}}\right)$. A polarization length constant $(\lambda)$ was used to relate the applied tACS electric field amplitude (see next section for electric field estimation) to a shift in the membrane potential. A study by Radman et al. (2009) showed that polarization is stronger in PyE neurons than in FSIs. Based on values from that study PyE neurons had a $\lambda$ of $0.2 \mathrm{~m}$ (i.e., tACS at $10 \mathrm{mV} / \mathrm{mm}$ produces a $2 \mathrm{mV}$ shift in the membrane potential), whereas FSIs had $\lambda$ of $0.1 \mathrm{~m}$. Note that Radman et al. (2009) also showed that a small number of FSIs had negative polarization values which our model does not take into account. The model was implemented in MATLAB (MathWorks) where Equation 1 was then solved for the population using the Euler method. Using this approach the number of FSI and PyE spikes for any rate of suprathreshold pulse-train stimulation combined with any subthreshold tACS amplitude and phase could be calculated.

To compare the leaky integrate-and-fire model results with the experimental data from the rat, the number of PyE spikes was calculated for a range of subthreshold tACS phases. Next the grand average number of PyE spikes across all phases was calculated, i.e., similar to the grand average in the rat data. Finally, model cortical excitability for each tACS phase was expressed at a percentage change from the grand mean number of PyE spikes. This is analogous to the approach used to calculate the changes in cortical excitability from accelerometer measurements made in the rat experiment.

Estimation of cortical electric field strength: electro-anatomical computational model. To estimate the magnitude of the electric field on the rat cortex during the stimulation, a rat head finite element model was generated. This allowed the estimation of the cortical electric field magnitude associated with both subthreshold and suprathreshold transcranial current stimulation (Datta et al., 2008, 2009; Rampersad et al., 2014). The model was created using rat brain which was previously segmented from a template consisting of the average T2 MRI scans from 30 Wistar rats (Valdés-Hernández et al., 2011). To obtain the skull for the model this template was imported to ScanIP 7 (Simpleware) where low level segmentation approaches were used. The CSF for the model was generated 
by adding a thin layer $(0.15 \mathrm{~mm}$ thickness $)$ around the brain. Using ScanIP, the skull, CSF and brain were combined and tetrahedral mesh elements were generated and exported to COMSOL Multiphysics 5. In COMSOL, the electrodes were defined as surfaces on the skull having the same dimensions and positions as the electrodes used in the rat experiment. The corresponding electrical conductive values $(\sigma)$ for the different tissues were assigned as follows: skull: $0.01 \mathrm{~S} / \mathrm{m}$; CSF: $1.65 \mathrm{~S} / \mathrm{m}$; and the brain: $0.2 \mathrm{~S} / \mathrm{m}$ (Gasca et al., 2011). Finally, the magnitudes of the electric field $(E)$ and current density $(J)$ were calculated by first solving Laplace's equation where $\varphi$ is the electrical potential.

$$
\begin{gathered}
E=|\nabla \phi| \\
J=\sigma|E| \\
n \nabla \cdot(\sigma \nabla \phi)=0 .
\end{gathered}
$$

This was done by setting the boundary conditions to have a $+1 \mathrm{~mA}$ current at the small electrode and $-1 \mathrm{~mA}$ at the large electrode.

Estimation of cortical electric field strength: in vivo measurements. To validate and calibrate the electro-anatomical model results, physical measurements of the electric potential in the rat brain were made at the end of three rat experiments, while the rat was still alive. We were especially interested in the electric field strength on the cortex directly under the stimulating electrode. However, drilling a hole in the skull to measure at that position would cause a large deviation from the electric field strength used during the experiment. Therefore, a small hole was drilled in the skull $1 \mathrm{~mm}$ anterior to the small disk electrode. A tungsten measurement electrode was inserted into the hole. A sine wave current of 4 $\mathrm{Hz}$ with an amplitude increasing in $0.1 \mathrm{~mA}$ steps from 0.1 to $1 \mathrm{~mA}$ was applied to the transcranial disk electrodes. Measurements of the potential difference between the tungsten electrode and a reference electrode placed on the rat's tail were then made at different penetration depths, starting at the cortical surface and moving down $3 \mathrm{~mm}$ in steps of $0.5 \mathrm{~mm}$ along the dorsal-ventral axis. The electric potential measured at each depth from the recording electrodes was digitized (NI USB-6216, National Instruments) at $20 \mathrm{kHz}$ sample rate and saved to MATLAB. The first spatial derivate of the measured voltage was then calculated to give the electric field component in one direction (i.e., the $x$-axis in the electro-anatomical model) at this specific brain location for a range of amplitudes from 0.1 to $1 \mathrm{~mA}$. As expected, the measured electric field strength scaled linearly with increasing current amplitude.

The measured electric field strength for $1 \mathrm{~mA}$ stimulation was then compared with the electric field strength from the same brain location in the electro-anatomical model (also at $1 \mathrm{~mA}$ ). The model electric field distribution for the complete brain could then be scaled to match that of the measured electric field at this specific location. This mixed approach to electric field estimation combined the advantages of the electroanatomical model (i.e., a good representation of the electric field distribution throughout the entire brain), with the advantages of in vivo measurements (i.e., an accurate measurement of electric field strength at only a few brain locations).

\section{Results}

tACS modulates cortical excitability in an amplitude and phase-dependent manner

The effect of subthreshold tACS on cortical excitability was assessed by inserting a suprathreshold pulse-train at different tACS phases and measuring limb movement with an accelerometer. The top line in Figure $2 A$ (black line with error bars) shows how cortical excitability changed in one rat when $2 \mathrm{~Hz}$ tACS was applied at $0.6 \mathrm{~mA}$ creating a relatively strong electric field estimated to be $48 \mathrm{~V} / \mathrm{m}$ (for details, see Estimation of the cortical electric field strength). In Figure $2 A$ the suprathreshold pulse-train used to probe cortical excitability was always presented at $2.7 \mathrm{~mA}$ with a rate of 300 pps. We found that one tACS phase caused a strong $48 \%$ decrease in cortical excitability, whereas the phase half a cycle later caused a strong $42 \%$ increase in excitability. When the subthreshold tACS amplitude was progressively reduced the effect on cortical excitability decreased and was absent when no tACS was applied ( $0 \mathrm{~mA})$. However, even for $0.1 \mathrm{~mA}$ tACS, estimated to create a relatively weak electric field of $8 \mathrm{~V} / \mathrm{m}$, a significant $21 \%$ decrease and $29 \%$ increase in cortical excitability could still be measured in this rat.

The maximum significant increase and decrease in cortical excitability is indicated with a white or black dot. Figure $2 \mathrm{~A}$ represents one complete dataset in one rat. In all 12 rats a total of 32 datasets covering tACS amplitudes from 0.1 to $0.6 \mathrm{~mA}$ (estimated to be $8-48 \mathrm{~V} / \mathrm{m}$ ), tACS frequencies from 2 to $6 \mathrm{~Hz}$, using suprathreshold pulse-trains with rates between 300 and 900 pps were collected. Figure $2 B$ shows the maximum significant increase and decrease in cortical excitability for all datasets. Lines join points that were collected in the same rat with the exactly same stimulation parameters, except for tACS amplitude (Fig. $2 A$ ). The example shown in Figure $2 A$ is highlighted as a gray line with stars. The effects of subthreshold tACS on cortical excitability clearly decreases with decreasing tACS amplitude. Linear regression analysis showed a significant correlation $(p<0.001)$ between the maximum increase and decrease in cortical excitability and subthreshold tACS amplitude (Fig. 2B, thick gray lines). On average a change in tACS amplitude of $0.1 \mathrm{~mA}$ lead to an increase or decrease in cortical excitability of $2.8 \%$, or a change in cortical electric field strength of $1 \mathrm{~V} / \mathrm{m}$ lead to a change in cortical excitability of $0.325 \%$. Last, Figure $2 B$ highlights the large variability in changes in cortical excitability induced by tACS. For example, at 0.4 and $0.6 \mathrm{~mA}$ some rats showing a relatively large change in cortical excitability while others show only a very small change.

A two-way ANOVA was conducted that examined the effect of tACS phase ( 9 levels: $0-1$ in steps of 0.125 cycles) and tACS amplitude (5 levels: $0,0.1,0.2,0.4,0.6 \mathrm{~mA}$ ) on cortical excitability. There was a statistically significant interaction between the effects of tACS phase and tACS amplitude on cortical excitability, $F_{(36,1061)}=1.48, p=0.036$. The main effects of tACS phase was significant $F_{(1,9)}=6.53, p<0.001$; as was the main effect of tACS amplitude $F_{(1,4)}=25.08, p<0.001$.

\section{tACS effects on cortical excitability are dependent on the rate of suprathreshold stimulation}

Results from the previous section showed that one subthreshold tACS phase increased cortical excitability, while the opposite phase decreased excitability. Having established this, we then examined the interaction between subthreshold tACS effects on cortical excitability and the rate of the suprathreshold pulsetrain. Figure 3 shows data from one rat were the subthreshold tACS waveform was held constant $(4 \mathrm{~Hz}, 0.4 \mathrm{~mA})$ and the suprathreshold pulse-train parameters were systematically varied. For each panel, the suprathreshold pulse-train always contained 10 pulses of $3 \mathrm{~mA}$, but the rate at which the pulses were delivered was changed from 300 to 800 pps. The effect of subthreshold tACS on cortical excitability was clearly dependent on the rate of the suprathreshold pulse-train. When the pulse-rate was low ( $\leq 600$ pps in this rat) cathodic subthreshold tACS decreased cortical excitability, whereas anodic subthreshold tACS increases cortical excitability. For higher rate suprathreshold stimulation ( $>600$ pps in this rat) this pattern was completely inverted with cathodic subthreshold tACS increasing cortical excitability and anodic subthreshold tACS decreasing cortical excitability.

Figure 4 (top two rows) shows data from two other rats where the effect of tACS on cortical excitably could be completely inverted by changing the rate of the suprathreshold pulse-train 

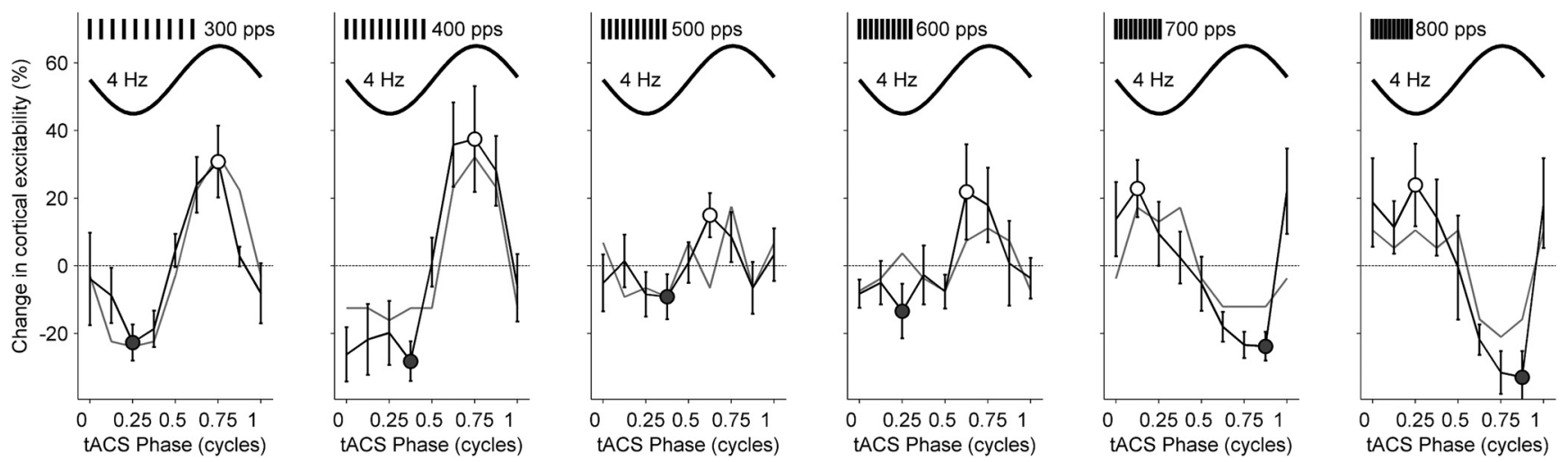

Figure 3. The effect of subthreshold $t A C S$ on cortical excitability changes as the rate of the suprathreshold pulse-train is increased. In each panel the subthreshold tACS was always delivered at $4 \mathrm{~Hz}$ and $0.4 \mathrm{~mA}$, but the suprathreshold pulse-train rate was changed from 300 to $800 \mathrm{pps}$. For a low-rate pulse-train ( $\leq 600 \mathrm{~Hz}$ for this rat) cathodic tACS decreased cortical excitability while anodic tACS increased cortical excitability. For high-rate pulse-trains ( $>600 \mathrm{~Hz}$ for this rat) the pattern was inverted with cathodic tACS increasing cortical excitability and anodic tACS decreasing it. Error bars, black and white dots, and straight dotted lines are the same as in Figure 2 . The gray lines show the integrate-and-fire model estimate of the changes in cortical excitability for these stimulation parameters. Note the times of the suprathreshold pulse-trains are not to scale.

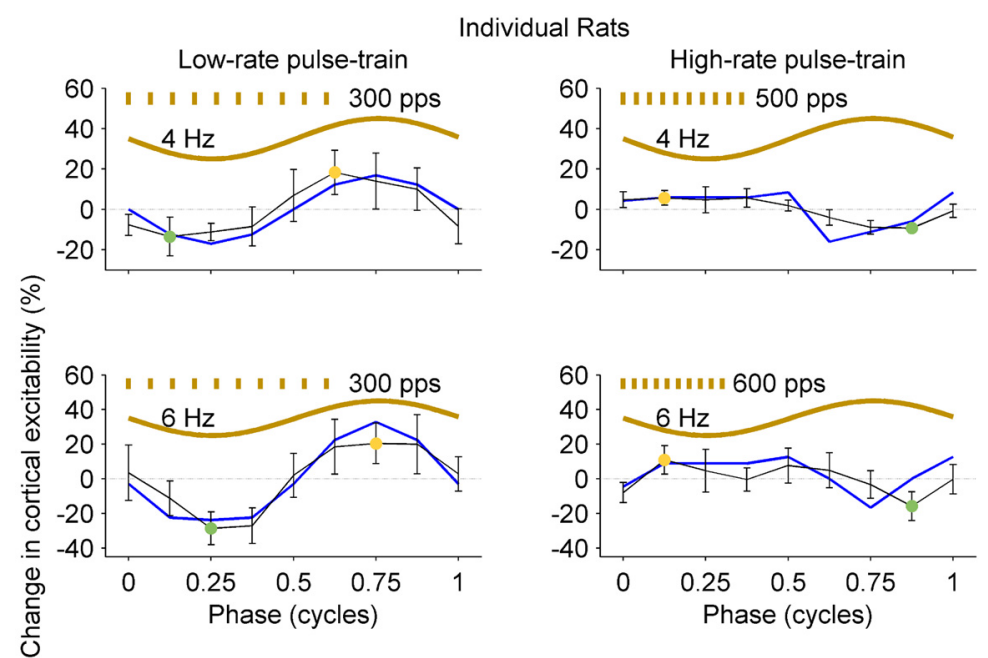

All Rats

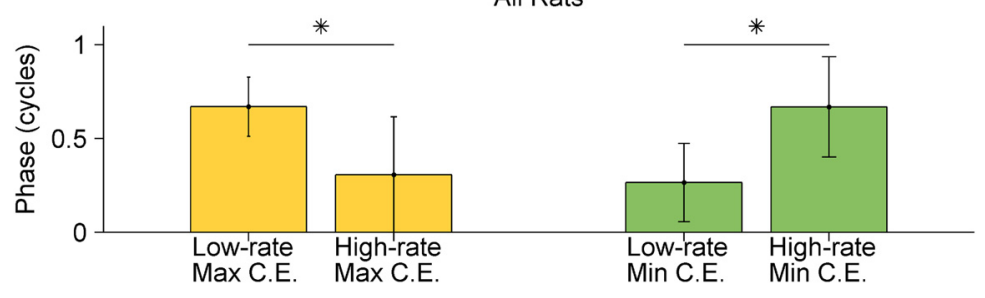

Figure 4. The effect of subthreshold tACS on cortical excitability is inverted if the cortex is excited using low- or high-rate pulse-trains. The first two rows compare low- and high-rate data from two rats (top row: $-4 \mathrm{~Hz}, 0.2 \mathrm{~mA}$; middle row: $-6 \mathrm{~Hz}, 0.4$ $\mathrm{mA}$ ). Error bars and dotted lines are the same as in Figure 2. Yellow and green dots now show the maximum increase and decrease in cortical excitability. The blue lines show the integrate-and-fire model estimate of the changes in cortical excitability for these stimulation parameters. The gold lines above the plots show the subthreshold and suprathreshold waveforms. Note the times of the suprathreshold pulse-trains are not to scale. The bar graph (bottom row, left) compares the mean phase at which the maximum increase in cortical excitability occurred for the low- and high-rate pulse train for all rats tested. The error bars show the SD. A paired $t$ test shows that there was a significant difference in the phase at which this occurs. The bar graph on the bottom right shows a similar significant difference in the phase at which the maximum decrease in cortical excitability occurs for the low- and high-rate pulse trains.

from low (left columns, $300 \mathrm{pps)}$ to high (right columns, 500 or $600 \mathrm{pps}$ in these rats). We collected data showing this effect in 11 rats. In all rats, when a 300 pps suprathreshold pulse-train was used cathodic tACS decreased cortical excitability and anodic tACS increases cortical excitability. In all rats the effect of subthreshold tACS on cortical excitability could be inverted by using higher rate suprathreshold pulse-trains. However, the rate at which this inversion occurred was not the same in all rats. The mean rate at which we observed this inversion was 600 pps ( 150 pps SD, $500-900$ pps range). The inversion occurred regardless of subthreshold tACS frequency. The bar graphs in Figure 4 (bottom row) summarizes these data for all rats tested. The mean phase at which the maximum increase (yellow dots, top rows) or maximum decrease (green dots, top rows) in cortical excitability occurred for a lowrate pulse-train (always $300 \mathrm{pps}$ ) is compared with the corresponding mean phase at which the maximum increase or decrease in cortical excitability occurred for a high-rate pulse-train $(600 \pm 150 \mathrm{pps})$. The error bars indicate SD. A paired $t$ test showed that there was a significant difference between the phase at which the maximum increase in cortical excitability occurred for a low-rate pulse-train compared with a high-rate pulse-train $(p<$ $0.001)$. A separate paired $t$ test show the same effect of pulse-train rate on the phase at which the maximum decrease in cortical excitability occurred $(p<0.001)$.

Figure 5 shows the results of the sine wave fitting procedure as a function of suprathreshold pulse-train rate for all data. In agreement with the results from Figure 4, Figure 5 (top) shows that when a lowrate pulse-train was used, data were best fit with a sine wave with a phase of 0.5 cycles (indicating that cathodic tACS decreases cortical excitability), whereas data for the high-rate pulse-trains (500-900 pps) were best fit with a sine wave with a phase of 0 cycles (indicating that cathodic tACS increased cortical excitability). Note that there were not enough data available to calculate a value at 400 pps. Figure 5 (bottom) shows the amplitude of the fitted sine wave giving an indication of how changes in cortical excitability 

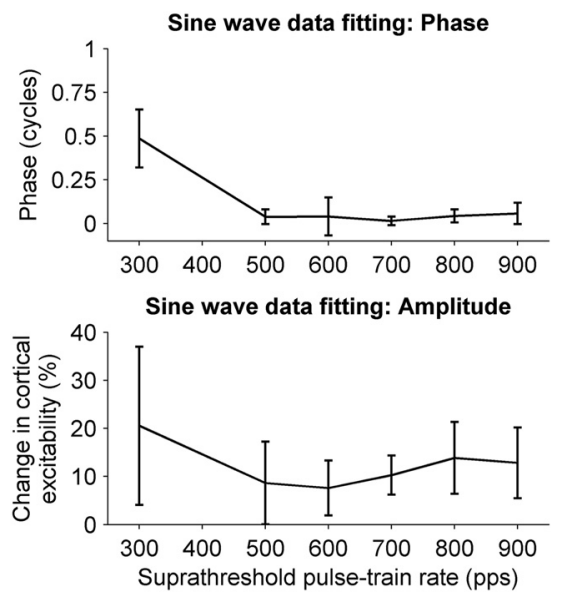

Figure 5. Fitted sine wave parameters (phase and amplitude) shown as a function of suprathreshold pulse-train rate (group mean for data from all rats, error bars show SD). Top, The fitted phase is close to 0.5 cycles for 300 pps (indicating that cathodic tACS decreases cortical excitability) and close to 0 for all higher-rates (indicating the cathodic ACS increases cortical excitability). Note, that not enough data are available at 400 pps to calculate a group mean. Bottom, The large changes in cortical excitability (>40\%) that were sometimes observed with 300 pps were not present with higher-rate pulse trains.

vary as a function of suprathreshold pulse-train rate. Note that the very large changes in cortical excitability present in some data at 300 pps (sometimes $>40 \%$ ) were not observed when high-rate suprathreshold pulse-trains were used.

\section{Integrate-and-fire population model}

An integrate-and-fire population model consisting of $100 \mathrm{PyE}$ neurons and 100 FSIs was implemented to help interpret the results from the rat experiment. The model parameters are shown in Table 2 and included biophysical differences between PyE neurons and FSIs; i.e., PyE neurons are more strongly polarized by subthreshold electric fields than FSIs (Tranchina and Nicholson, 1986; Radman et al., 2009) and PyE neurons have a lower input resistant, longer membrane time constant and longer refractory period than FSIs (Connors and Gutnick, 1990; Kawaguchi, 1993, 1995; Thomson, 1997; Beierlein et al., 2003; Compte et al., 2003; Povysheva et al., 2006). Note, the model simulates the indirect suprathreshold route (i.e., presynaptic action potential initiation in PyE neurons and FSIs) but not the direct route (i.e., postsynaptic action potential initiation in PyE neurons), which is less likely to be influenced by subthreshold tACS.

Figure 6 illustrates how the population of model PyE neurons and FSIs behaved when suprathreshold pulse-train stimulation was applied at different rates. All pulse-trains consisted of 10 pulses, just as in the rat experiments. To isolate the effects of pulse-train rate on each neuron type, for all the plots shown in Figure 6, the neurons were not synaptically coupled to one another (i.e., $w=0$ ). Figure $6 \mathrm{~A}$ shows action potential initiation threshold for the PyE (red) and FSI (blue) populations expressed as a compound EPSP amplitude. As the pulse-train rate increased the threshold decreased for both PyE neurons and FSIs. This is due to temporal summation of EPSPs; as the pulses come closer together EPSPs overlap more meaning that smaller amplitude EPSPs are needed to reach threshold potential. Interestingly, the FSI threshold was higher than the PyE threshold for all pulsetrain rates. The inset shows equal amplitude compound EPSPs elicited to just a single pulse for one PyE neuron and one FSI. Because of the faster membrane time constant the EPSP halfwidth for the FSI is $8 \mathrm{~ms}$, whereas that of the PyE is $17 \mathrm{~ms}$. This is a result of the faster membrane time constant in the FSIs and leads to less temporal summation of EPSPs.

Note, because of the difference in membrane time constants, to achieve a compound EPSP of $5 \mathrm{mV}$ in a PyE neuron a compound synaptic conductance $\left(g_{a}\right)$ of $0.018 \mathrm{nS}$ was needed, whereas in an FSI a compound synaptic conductance of $0.0513 \mathrm{nS}$ was needed. In vitro work has shown that the single EPSPs in rat motor cortex FSIs have an amplitude of $\sim 0.5 \mathrm{mV}$, whereas rat motor cortex PyE neurons have an amplitude of $\sim 1 \mathrm{mV}$ (Thomson, 1997). Our model is based on compound EPSPs created by single EPSPs arriving synchronously from multiple presynaptic inputs. However, we do not have a good estimate of the number of presynaptic inputs contributing to one compound EPSP nor do we know how this may differ between FSIs and PyE neurons. Therefore, in the rest of our simulations we fixed the compound EPSP amplitude elicited to a single pulse to be $5 \mathrm{mV}$ in both PyE neurons and FSIs. This means we should be cautious about drawing quantitative conclusions from the model. Nevertheless, this approach will give us valuable insight into physiologically plausible neural mechanisms which may generate the patterns of data observed in the rat experiment.

Figure $6 B$ shows the total number of spikes when the population of neurons is stimulated with $5 \mathrm{mV}$ compound EPSPs for a range of different pulse-train rates. When stimulated at 200 and 300 pps the FSIs did not fire any action potentials but the PyE neurons did. Increasing the pulse-train rate lead to more temporal summation in the FSIs causing them to fire progressively more action potentials. Figure $6, C$ and $D$, shows the membrane potential for one PyE neuron and one FSI in response to pulse-trains with 300 and 700 pps. This illustrates how differences in temporal summation of EPSPs (due to membrane time constants) cause the different response curves shown in Figure $6 B$.

In Figure $6 B$, the lightly shaded areas show how the addition of $30 \mathrm{~V} / \mathrm{m}$ tACS, fixed at either the maximum positive or negative phase, can increase or decrease the number of action potentials. The bump in the PyE curve $\sim 300$ and 400 pps was caused by some neurons firing two action potentials in response to one pulse-train. This was not possible with higher rate pulse-trains because these pulse-trains have a shorter duration. Because of the shorter refractory period imposed in the model, FSIs can fire more action potentials to one pulse-train resulting in a smoother curve.

Figure 7 shows the effects when the PyE and FSI populations were synaptically coupled, i.e., each PyE neuron now receives inhibitory input for 10 FSIs. Subthreshold tACS at $30 \mathrm{~V} / \mathrm{m}$ was applied and a 300 pps (Fig. 7A) or 700 pps (Fig. 7B) suprathreshold pulse-train was used to probe cortical excitability. Note, only three phases $(0.25,0.5$, and 0.75$)$ of the tACS cycle are shown corresponding to $-30,0$, and $30 \mathrm{~V} / \mathrm{m}$. Synaptic efficiency $(w)$ was set to 1 . The membrane potential of two illustrative PyE neurons (top row) and one FSI (bottom row) are shown and the total number of spikes for each neuron type under each stimulation condition is reported in the bottom corner of the panel. When a low-rate suprathreshold pulse-train was used to probe cortical excitability FSIs did not reach threshold. Therefore, a cathodic tACS phase simply hyperpolarized the membrane potential of the PyE neurons leading to fewer spikes and a decrease in cortical excitability. Similarly, when an anodic tACS phase was applied the membrane potential was depolarized leading to more PyE spikes and an increase in cortical excitability. However, when a high-rate suprathreshold pulse-train was used FSIs did reach threshold. By causing small changes in the FSI membrane potential tACS had two important effects: one on the total number of 

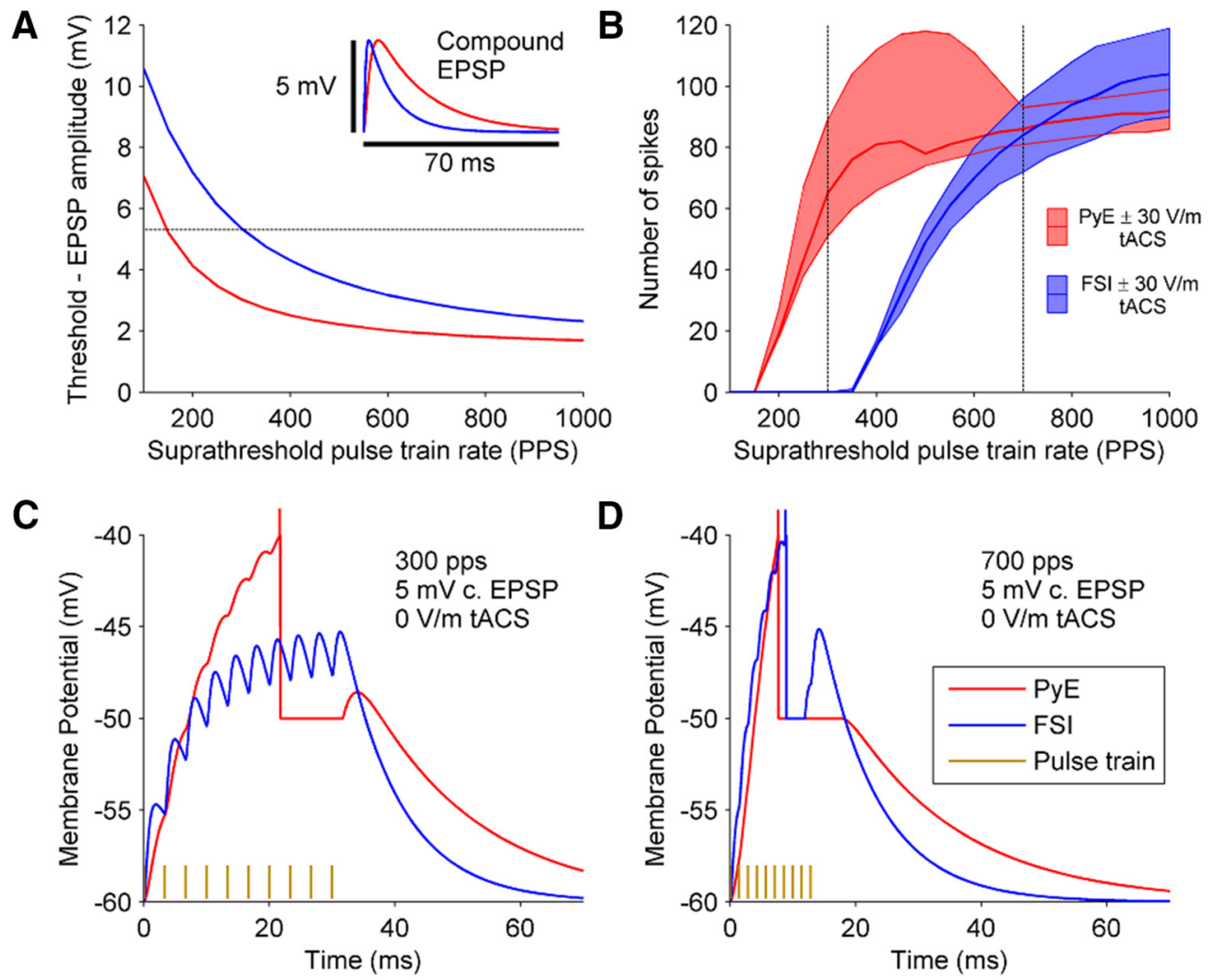

Figure 6. Integrate-and-fire-model: a characterization of PyE and FSIs when no synaptic coupling is present (i.e., FSI inhibition of PyE neurons). $\boldsymbol{A}$, The action potential thresholds as a function of the suprathreshold pulse-train rate for PyE (red line) and FSI (blue line). Inset, An example of one PyE and one FSI compound EPSP elicited to a single pulse. For a 300 pps pulse-train, EPSPs at this amplitude would be suprathreshold for PyE neurons but subthreshold for FSIs (dashed line). $\boldsymbol{B}$, When presynaptically stimulated with pulse-trains that cause equal amplitude EPSPs (5 mV), the number of action potentials fired by PyE and FSI populations changes differently as the suprathreshold pulse-train rate is increased. The light shaded areas show how $30 \mathrm{~V} / \mathrm{m}$ subthreshold tACS can increase (anodic phase) or decrease (cathodic phase) the number of spikes. C, For low-rate pulse-trains ( 300 pps, gold line, amplitude not to scale) FSIs do not reach spiking threshold because of their shorter membrane time constant causing less temporal summation. D, For high-rate pulse-trains (700 pps, gold line, amplitude not to scale) both PyE neurons and FSIs reach spiking threshold.

FSI spikes and one on the timing of FSI spikes. Cathodic tACS caused a decrease in the number of FSI spikes and made them occur slightly later, whereas anodic tACS caused an increase in the number of FSI spikes and made them occur slightly earlier. Under these stimulation conditions inhibition effects dominate the model output. Less FSI spikes occurring later leads to a reduction in inhibition of PyE neurons and thus an increase in the total number of PyE spikes compared with the $0 \mathrm{~V} / \mathrm{m}$ tACS condition. Although, more FSI spikes occurring earlier lead to an increase in inhibition of PyE neurons and thus a decrease in the total number of PyE spikes compared with the $0 \mathrm{~V} / \mathrm{m}$ tACS condition. Thus, the integrate-and-fire model offers a physiologically plausible explanation for the inversion of the effects of tACS on cortical excitability when a high-rate suprathreshold pulse-train is used.

We ran the integrate-and-fire population model for the range of suprathreshold pulse-trains (300-800 pps) and subthreshold tACS phases $(0-1$ in steps of 0.125 cycles) and amplitudes $(0.4$ $\mathrm{mA}$ or $32 \mathrm{~V} / \mathrm{m}$ ) shown in Figure 3 and calculated the change in cortical excitability from the number of PyE action potentials. The model predicted change in cortical excitability for each suprathreshold stimulation rate is shown as a gray line on each panel in Figure 3. The model captures many of the features observed in the rat experimental data. A low-rate suprathreshold pulse-train (300 pps) caused excitation-dominated activity, meaning that subthreshold cathodal tACS decreased cortical excitability and anodal tACS increased excitability. However, a high-rate suprathreshold pulse-train (>600 pps) caused inhibition-dominated activity, meaning that subthreshold cathodal tACS increased cortical excitability and anodal tACS decreased excitability. Suprathreshold pulse-trains with intermediate rates (400 and $500 \mathrm{pps)}$ caused balanced excitation and inhibition, meaning that subthreshold tACS had little net effect on cortical excitability.

For the model data shown in Figure 3 the synaptic efficiency $(w)$ was set to 1 . In general, increasing the strength of the synaptic efficiency causes the model to shift to inhibition-dominated activity at lower rates. The synaptic efficiency for the model was manually adjusted to give the best fit to the experimental data shown in Figure 4. The main features of the experimental data shown in Figure 4 (top row) were well accounted for by the integrate-and-fire population model when the synaptic efficiency was increased to 2 and the model tACS electric field strength set to $16 \mathrm{~V} / \mathrm{m}$ to match the $0.2 \mathrm{~mA}$ tACS used in the rat experiment to collect these data. Setting the synaptic efficiency to 1.7 and the model tACS electric field to $30 \mathrm{~V} / \mathrm{m}$ matched the data shown in Figure 4 (second row; $0.4 \mathrm{~mA}$ tACS was used in the rat experiment to collect these data). The number of synaptic connections between FSIs and PyE neurons is known to be highly variable (Wang et al., 2002; Markram et al., 2004) and the strength of these synaptic connections can change due to learning and experience (i.e., synaptic plasticity; Vogels et al., 2013). This may explain why different synaptic efficiency values were needed to explain the observed experimental results in different rats.

Figure 2 showed how changes in cortical excitability decreased as tACS amplitude was decreased. The integrate-and-fire model 

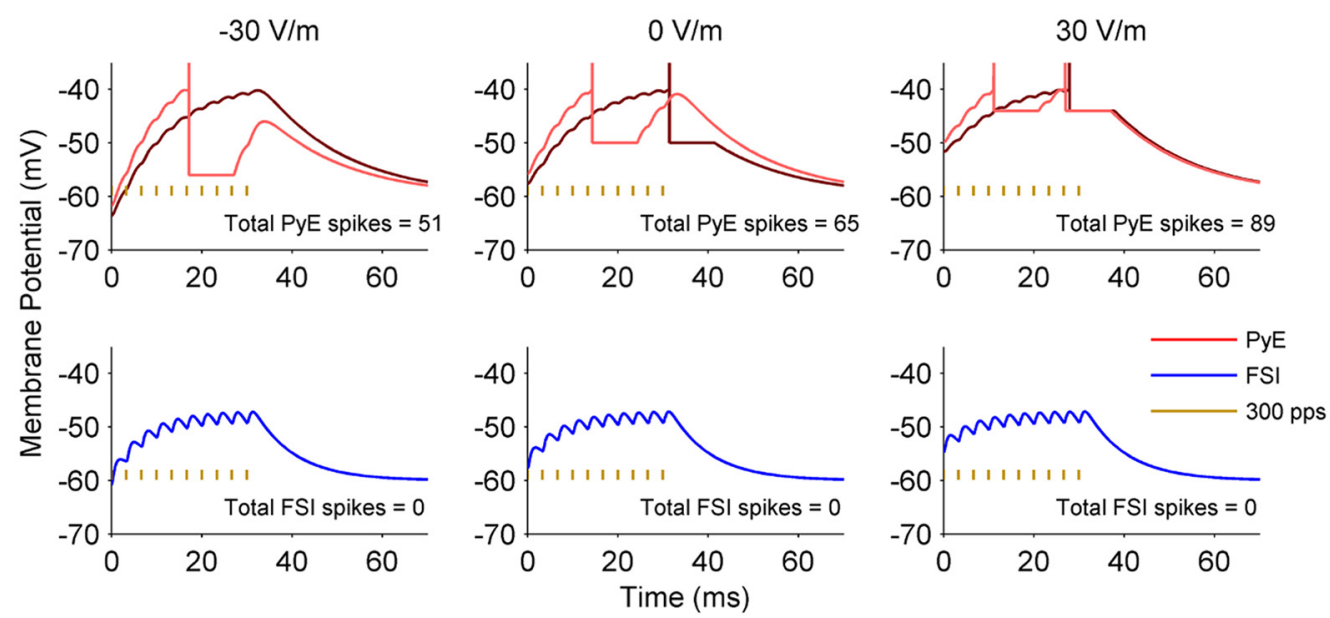

B

700 pps suprathreshold pulse-train
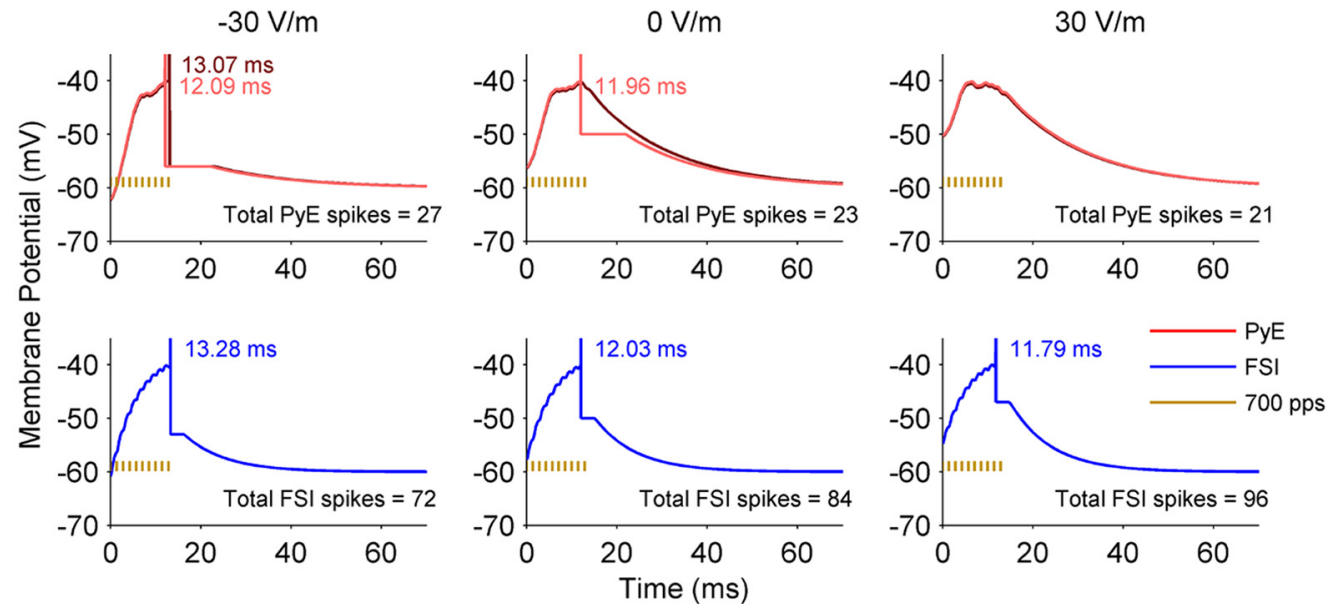

Figure 7. Integrate-and-fire model: the pulse rate-dependent inhibitory input causes an inversion of subthreshold tACS effects with a high-rate suprathreshold pulse-trains. $A$, The top row shows the membrane potential from two example PyE neurons and the bottom row shows one example FSI. The text insets report the total number of PyE and FSI spikes. With a low-rate pulse-train (300 pps) FSIs do not reach threshold. Cathodal tACS (left) simply hyperpolarizes the membrane decreasing the number of PyE spikes, whereas anodal tACS (right) depolarizes the membrane increasing the number of spikes. $\boldsymbol{B}$, With a high-rate pulse-train (700 pps) FSIs reach threshold and fire spikes. Cathodal tACS both decreases the number of FSI spikes and makes them occur later, whereas anodal $\mathrm{tACS}$ increases the number of FSI spikes and makes them occur earlier. This leads to an inhibition-dominated population causing an inversion of the subthreshold tACS effects as measured via the total number of PyE spikes.

could also account for this general trend (Fig. 2A, gray lines). For subthreshold tACS at $8 \mathrm{~V} / \mathrm{m}$ the model predicted changes in cortical excitability of $\pm 10 \%$. This is lower than the changes in cortical excitability measured for $0.1 \mathrm{~mA}$ (estimated to be $8 \mathrm{~V} / \mathrm{m}$ ) tACS in the particular example data shown in Figure $2 A$. However, it is reasonable agreement with the average change in cortical excitability across all rats for $0.1 \mathrm{~mA}$ tACS (Fig. 2B). The data in Figure $2 A$ actually show an increase in cortical excitability at 0.25 cycles when tACS amplitude is decreased from 0.2 to 0.1 . The model predicts linear decreases in cortical excitability as tACS amplitude is decreased and cannot capture these nonlinearities observed in the data.

Estimation of the cortical electric field strength

As shown in Figure 2, the neuromodulatory effects of tACS are highly dependent on the current amplitude and thus the electric field strength that reaches the cortex. However, the strength of the electric field is influenced by a number of factors including head size, skull thickness, and electrode location. Therefore, a good estimate of the cortical electric field strength is necessary.

The in vivo electric field measurements made $1 \mathrm{~mm}$ anterior to the stimulating electrode showed an $x$-axis (corresponding to the ventral-dorsal axis) electric field component at the cortical surface of $25 \pm 5 \mathrm{~V} / \mathrm{m}$ (mean $\pm \mathrm{SD}, n=3$ ) when $1 \mathrm{~mA}$ of current was applied to the transcranial electrodes. At the same location the electroanatomical model showed an $x$-axis electric field component of 31 $\mathrm{V} / \mathrm{m}$ for $1 \mathrm{~mA}$ of current. This means that the electro-anatomical model overestimated the electric field strength in the brain by $\sim 23 \%$. The overestimation of the electro-anatomical model may due to skull surface current paths that allow some current to pass directly between the electrodes without entering the head. These paths were not accounted for in the electro-anatomical model. It may also be due to differences in skull and CSF thickness between the electro-anatomical model and the rat used in the experiments.

The electro-anatomical model assumes a quasi-static approximation of Maxwell's equations, which is valid for alternating 


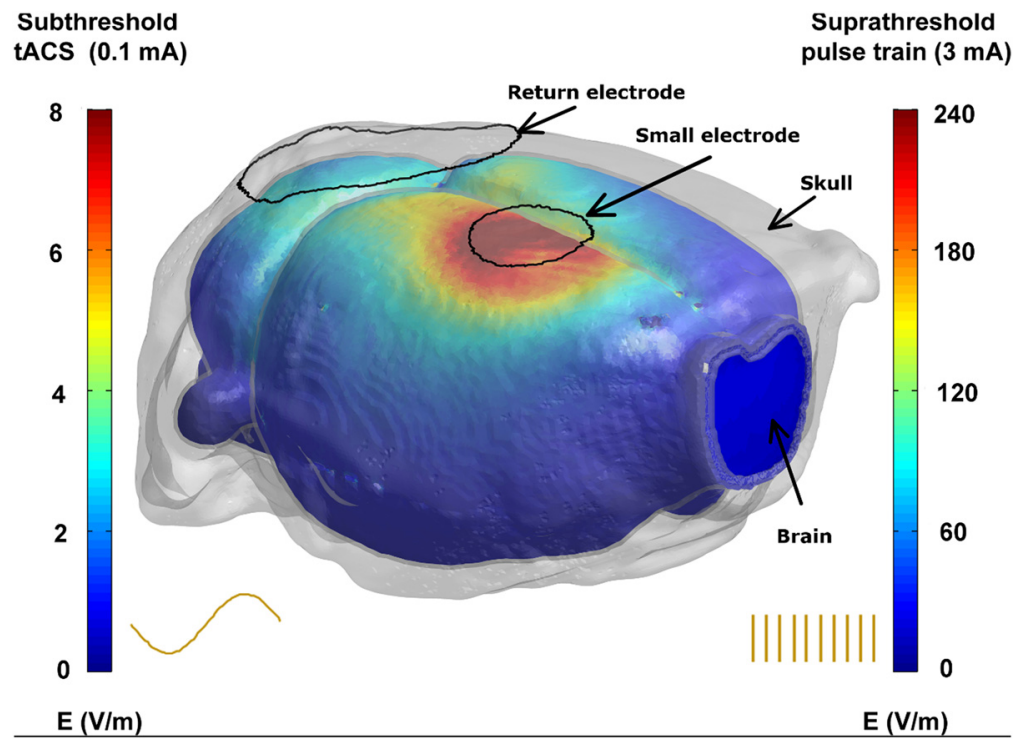

Figure 8. MRI-based electro-anatomical computational model showing the electric field magnitude distribution on the cortical surface when transcranial current stimulation is applied. This linear model assumes a quasi-static approximation of Maxwell's equations which is valid for alternating electric fields in the brain within the frequency ranges of both the subthreshold and suprathreshold threshold stimuli. Thus, the same model data can be scaled to show the strength of the subthreshold (left colorbar) and suprathreshold (right colorbar) electric field distributions. The model shows that the use of a small stimulating electrode and larger return electrode ensures that maximum electric field strength is reached under the stimulating electrode. Gold insets show the subthreshold and suprathreshold stimuli waveforms (not to scale).

electric fields in the brain within the frequency ranges of both the subthreshold and suprathreshold threshold stimulation (Nunez and Srinivasan, 2006). Consequently, the same electric field distribution, but with different magnitude scales, can be used to represent both subthreshold tACS and suprathreshold pulsetrain stimulation. Thus, Figure 8 shows the model predicated electric field distribution, with the scale on the left showing the magnitude of the electric field for subthreshold tACS stimulation at $0.1 \mathrm{~mA}$ and the scale on the right showing the electric field distribution for suprathreshold pulse-train stimulation at $3 \mathrm{~mA}$. Both scales have been corrected for the $23 \%$ over estimation of the electro-anatomical model.

The results show that the strongest electric field in the cortical area under the small electrode was of $240 \mathrm{~V} / \mathrm{m}$ for suprathreshold pulse-train stimulation at $3 \mathrm{~mA}$ and $8 \mathrm{~V} / \mathrm{m}$ for subthreshold tACS at $0.1 \mathrm{~mA}$.

\section{Discussion}

Our experiments show that the effect of low-frequency subthreshold tACS on cortical excitability is complex; applying the same subthreshold tACS waveform to the same cortical area does not always have the same effect on cortical excitability. Instead, the effect of tACS on cortical excitability was highly dependent on the parameters of the suprathreshold pulse-train used to probe cortical excitability. When a low-rate, long duration, suprathreshold pulse-train was used a cathodic tACS phase decreased cortical excitability and an anodic tACS phase increased excitability. However, when a high-rate, short duration, suprathreshold pulse-train was used this pattern was inverted with a cathodic tACS phase increasing cortical excitability and an anodic tACS phase decreasing excitability. Consideration of the known biophysical differences between PyE neurons and FSIs offers a physiologically plausible explanation for these results, in addition to giving interesting insight into potential mechanisms underlying cortical electrical stimulation.
To illustrate this, we implemented an integrate-and-fire population model in which FSIs had a lower membrane time constant than PyE neurons (Connors and Gutnick, 1990; Kawaguchi, 1993, 1995; Thomson, 1997; Beierlein et al., 2003; Compte et al., 2003; Povysheva et al., 2006). When presynaptically stimulated with a pulse-train the FSIs showed less temporal summation and thus a higher spiking threshold than PyE neurons (Fig. 6A). When presynaptically stimulated with pulsetrains causing equal amplitude EPSPs, the number of spikes fired by each neuron type changed differently as a function of pulsetrain parameters: longer, low-rate pulsetrains caused PyE neurons to reach spiking threshold but not FSIs; whereas shorter, high-rate pulse-trains caused both PyE neurons and FSIs to reach threshold (Fig. 6B). The FSIs were then synaptically coupled to the PyE neurons and the effects of subthreshold tACS studied. The integrate-andfire model could explain many of the observed patterns in the data (Figs. 2, 3, 4, gray/blue lines). The model indicated that changing suprathreshold pulse-train parameters could change the excitation-inhibition balance within a cortical circuit: a longer, low-rate pulse-train caused excitation-dominated activity, whereas a shorter, high-rate pulse-train caused inhibition-dominated activity. The model showed that this mechanism could explain the inversion in the effects of tACS on cortical excitability observed in the rat experiments.

\section{Similarities with transcranial magnetic stimulation}

TMS uses a pulsed magnetic field to induce a suprathreshold current pulse in the cortex. TMS can probe cortical excitability and paired pulse TMS paradigms can selectively modulate cortical excitability (Di Lazzaro and Rothwell, 2014). When the interval between the pulses is short ( $1-5 \mathrm{~ms}$, corresponding to a rate of 200-1000 pps), and the first pulse is subthreshold, cortical excitability as measured with the second pulse is decreased. This phenomenon is known as short-interval intracortical inhibition (SICI) and is believed to be facilitated through activation of inhibitory interneurons (Ziemann et al., 1996). Conversely, when the interval between the pulses is long (10-25 ms, 40-100 pps), cortical excitability as measured with the second pulse is increased. This is known as intracortical facilitation (ICF). In a recent study $20 \mathrm{~Hz}$ tACS was applied to the motor cortex in healthy volunteers and cortical excitability probed at different tACS phases using single-pulse ICF and SICI TMS (Guerra et al., 2016). They showed that $20 \mathrm{~Hz}$ tACS modulates cortical excitability in a phase-dependent way but interestingly the effect of tACS was dependent on the TMS paradigm. A tACS phase that increased cortical excitability when probed with single pulse or ICF actually decreased cortical excitability when probed with SICI. Thus, the findings of Guerra et al. (2016) support our interpretation of the results from the rat experiment.

\section{Subthreshold tACS}

When applied to healthy volunteers subthreshold tACS modulates perception (Kanai et al., 2008), cognition (Marshall et al., 
2006), motor function (Pogosyan et al., 2009; Heise et al., 2016), and brain oscillations (Helfrich et al., 2014; Ruhnau et al., 2016). tACS reduces tremor in Parkinson's disease patients (Brittain et al., 2013) and reduces tinnitus (Vanneste et al., 2013). In humans tACS is typically applied at an amplitude of $2 \mathrm{~mA}$ which is estimated to cause an electric field of $\sim 0.5 \mathrm{~V} / \mathrm{m}$ in the cortex (Dmochowski et al., 2011; Opitz et al., 2016; Huang et al., 2017). In our rat experiments we could reliably measure significant changes in cortical excitability with currents of $0.1 \mathrm{~mA}$, which we estimated to cause an electric field strength of $8 \mathrm{~V} / \mathrm{m}$ in the cortex. In a few isolated examples (data not shown) we could measure significant changes in cortical excitability at $0.05 \mathrm{~mA}$ (or $4 \mathrm{~V} / \mathrm{m}$ ) but this was not possible in every animal. This may be due to the effects of anesthesia, although we did take care to maintain a light level of anesthesia (clear toe-pinch reflex). It is has been shown in humans that the effects of transcranial direct current stimulation at $2 \mathrm{~mA}$ are highly variable (Wiethoff et al., 2014), and the same has been anecdotally reported for tACS. Importantly, our results indicated that increasing the current amplitude increases the neuromodulatory effect of tACS and may reduce variability. Using standard tACS protocols in humans this not possible, since the current must first pass through the skin and stimulating at amplitudes $>2 \mathrm{~mA}$ will activate pain nerves in the scalp. However, we have recently used topical anesthetics in healthy volunteers to apply tACS at much higher amplitudes (A. Khatoun, B. Asamoah, and M. Mc Laughlin, unpublished observations) and used a computational model to show how subcutaneous placed tACS electrodes can achieve much stronger electric fields (Khatoun and Mc Laughlin, 2017).

\section{Polarization of pyramidal and interneurons}

Our integrate-and-fire model assumed that subthreshold tACS polarizes both pyramidal and interneurons, but that the polarization effects were stronger in pyramidal neurons. One study (Radman et al., 2009) measured the effects of a weak electric field on membrane polarization of pyramidal and interneurons in rat brain slices. Pyramidal neurons showed an average polarization length constant of $\sim 0.15 \mathrm{~mm}$ (i.e., $1 \mathrm{mV} / \mathrm{mm}$ causes membrane polarization of $0.15 \mathrm{mV}$ ) although there was considerable variation. Interneurons showed an average polarization length constant of $0 \mathrm{~mm}$, mainly because some interneurons had negative length constants (i.e., a positive electric field hyperpolarizes the membrane). Taking just the interneurons from Radman et al.'s (2009) experiments with a positive length constant gives an average length constant of $0.8 \mathrm{~mm}$. If the FSIs in our model showed no polarization due to tACS, the model could not explain the inverted tACS effects. Thus, some polarization of the FSIs was necessary to explain the experimental data. It is worth noting that Radman et al. (2009) made their measurements in a uniform electric field. In such a field, a neuron with perfectly spherically oriented dendrites has zero membrane polarization at the soma. However, in a nonuniform field there is some polarization at the soma. In our experiments the position of the stimulating and return electrodes above the brain meant that the electric field in the cortex was not uniform (Fig. 8). Although the non-uniformity at the neural scale will be small, it may be enough to polarize interneurons.

\section{Controlling the cortical excitation-inhibition balance using suprathreshold pulse-train stimulation}

Results from the rat experiment showed that the effect of subthreshold tACS on cortical excitability was highly dependent on the parameters of suprathreshold pulse-train. Changing the su- prathreshold pulse-train parameters could flip one tACS phase from increasing to actually decreasing cortical excitability. Results from the integrate-and-fire model offered a potential explanation for the observed effect: when presynaptically stimulated with longer, low-rate pulse-trains the action potential threshold in FSIs is higher than in PyE neurons. When presynaptically stimulated with shorter, high-rate pulse-trains the thresholds for both neuron types are closer. Thus, adjustment of simple pulse-train parameters may allow selective control of the cortical excitationinhibition balance.

We tested the effect of different pulse-train rates and balanced each pulse-train to have exactly the same number of pulses (10) and thus the same net charge. This meant that by design higherrate pulse-trains had a shorter duration than low-rate pulsetrains. Thus, based on the current data we cannot separate the effects of pulse-train rate from pulse-train duration. Further experimental and modeling studies are needed to tease apart the effects of rate and duration.

\section{Potential clinical applications}

Direct cortical stimulation (DCS) is an invasive neuromodulation method where electrodes are chronically implanted on the dura to deliver pulse-train stimulation. Motor cortex DCS can treat medically refractory neuropathic pain and is successful in $40-50 \%$ of patients (Tsubokawa et al., 1991, 1993; Nuti et al., 2005). Motor cortex DCS has been used to treat Parkinson's disease and can relieve a range of symptoms in some patients (Priori and Lefaucheur, 2007; Moro et al., 2011; Picillo et al., 2015). If our interpretation of the experimental results is correct and changing pulse-train parameters can control the excitation-inhibition balance within cortical circuits, then it may be possible to develop stimulation waveforms that can selectively target either excitatory or inhibitory elements within a cortical circuit and improve therapeutic outcomes. Although it should be cautioned that our results are from the rat which has a smooth cortex, whereas humans have a folded cortex which will alter current flow patterns.

\section{Conclusions}

Our results give new insight into the neural mechanisms through which subthreshold tACS affects cortical excitability. We showed that the effect of tACS on cortical excitability is complex: stimulating the same cortical area with the same tACS waveform does not always have the same effect on cortical excitability; rather the effect of tACS on cortical excitability is probably affected by the underlying balance between cortical excitation and inhibition. Experimental designs that manipulate the cortical excitation-inhibition balance using pharmacology (Ziemann, 2004) or TMS paradigms (Di Lazzaro and Rothwell, 2014) may provide a more controlled neural environment in which to study tACS effects in humans.

\section{References}

Ali MM, Sellers KK, Fröhlich F (2013) Transcranial alternating current stimulation modulates large-scale cortical network activity by network resonance. J Neurosci 33:11262-11275. CrossRef Medline

Antal A, Paulus W (2013) Transcranial alternating current stimulation (tACS). Front Hum Neurosci 7:317. CrossRef Medline

Ascoli G, Alonso-Nanclares L, Anderson SA, Barrionuevo G, BenavidesPiccione R, Burkhalter A, Buzsáki G, Cauli B, Defelipe J, Fairén A, Feldmeyer D, Fishell G, Fregnac Y, Freund TF, Gardner D, Gardner EP, Goldberg JH, Helmstaedter M, Hestrin S, Karube F, et al. (2008) Petilla terminology: nomenclature of features of GABAergic interneurons of the cerebral cortex. Nat Rev Neurosci 9:557-568. CrossRef Medline 
Beierlein M, Gibson JR, Connors BW (2003) Two dynamically distinct inhibitory networks in layer 4 of the neocortex. J Neurophysiol 90:29873000. CrossRef Medline

Brittain JS, Probert-Smith P, Aziz TZ, Brown P (2013) Tremor suppression by rhythmic transcranial current stimulation. Curr Biol 23:436-440. CrossRef Medline

Buzsáki G (2006) Cycle 3. In: Rhythms of the brain, pp 61-79. New York: Oxford UP.

Chen R (2004) Interactions between inhibitory and excitatory circuits in the human motor cortex. Exp Brain Res 154:1-10. CrossRef Medline

Compte, Sanchez-Vives MV, McCormick DA, Wang XJ A et al. (2003) Cellular and network mechanisms of slow oscillatory activity. J Neurophysiol 89:2707-2725. CrossRef Medline

Connors BW, Gutnick MJ (1990) Intrinsic firing patterns of diverse neocortical neurons. Trends Neurosci 13:99-104. CrossRef Medline

Datta A, Elwassif M, Bikson M (2008) Electrical stimulation of brain using a realistic 3D human head model: improvement of spatial focality. Proceedings of the COMSOL Conference 2008, Boston.

Datta A, Bansal V, Diaz J, Patel J, Reato D, Bikson M (2009) Gyri-precise head model of transcranial direct current stimulation: improved spatial focality using a ring electrode versus conventional rectangular pad. Brain Stimul 2:201-207, 207.e1. CrossRef Medline

Deans JK, Powell AD, Jefferys JG (2007) Sensitivity of coherent oscillations in rat hippocampus to AC electric fields. J Physiol 583:555-565. CrossRef Medline

DeFelipe J, Fariñas I (1992) The pyramidal neuron of the cerebral cortex: morphological and chemical characteristics of the synaptic inputs. Prog Neurobiol 39:563-607. CrossRef Medline

Di Lazzaro V, Rothwell JC (2014) Corticospinal activity evoked and modulated by non-invasive stimulation of the intact human motor cortex. J Physiol 592:4115-4128. CrossRef Medline

Di Lazzaro V, Ziemann U, Lemon RN (2008) State of the art: physiology of transcranial motor cortex stimulation. Brain Stimul 1:345-362. CrossRef Medline

Dmochowski JP, Datta A, Bikson M, Su Y, Parra LC (2011) Optimized multi-electrode stimulation increases focality and intensity at target. J Neural Eng 8:46011. CrossRef Medline

Fröhlich F, McCormick DA (2010) Endogenous electric fields may guide neocortical network activity. Neuron 67:129-143. CrossRef Medline

Galarreta M, Hestrin S (1998) Frequency-dependent synaptic depression and the balance of excitation and inhibition in the neocortex. Nat Neurosci 1:587-594. CrossRef Medline

Gasca F, Marshall L, Binder S, Schlaefer A, Hofmann UG, Schweikard A (2011) Finite element simulation of transcranial current stimulation in realistic rat head model. 2011 5th International IEEE/EMBS Conference on Neural Engineering, Cancun, 2011, pp 36-39. CrossRef

Gerstner W, Kistler WM (2002) Spiking neuron models: single neurons, populations, plasticity. Cambridge, UK: Cambridge UP.

Gibson JR, Beierlein M, Connors BW (1999) Two networks of electrically coupled inhibitory neurons in neocortex. Nature 402:75-79. CrossRef Medline

Guerra A, Pogosyan A, Nowak M, Tan H, Ferreri F, Di Lazzaro V, Brown P (2016) Phase dependency of the human primary motor cortex and cholinergic inhibition cancelation during beta tACS. Cereb Cortex 26:39773990. CrossRef Medline

Gupta A, Wang Y, Markram H (2000) Organizing principles for a diversity of GABAergic interneurons and synapses in the neocortex. Science 287: 273-278. CrossRef Medline

Heise KF, Kortzorg N, Saturnino GB, Fujiyama H, Cuypers K, Thielscher A, Swinnen SP (2016) Evaluation of a modified high-definition electrode montage for transcranial alternating current stimulation (tACS) of precentral areas. Brain Stimul 9:700-704. CrossRef Medline

Helfrich RF, Schneider TR, Rach S, Trautmann-Lengsfeld SA, Engel AK, Herrmann CS (2014) Entrainment of brain oscillations by transcranial alternating current stimulation. Curr Biol 24:333-339. CrossRef Medline

Huang Y, Liu AA, Lafon B, Friedman D, Dayan M, Wang X, Bikson M, Doyle WK, Devinsky O, Parra LC (2017) Measurements and models of electric fields in the in vivo human brain during transcranial electric stimulation. Elife 6:e18834. CrossRef Medline

Hussin AT, Boychuk JA, Brown AR, Pittman QJ, Campbell Teskey GC (2015) Intracortical microstimulation (ICMS) activates motor cortex layer 5 pyramidal neurons mainly transsynaptically. Brain Stimul 8:742750. CrossRef Medline

Kanai R, Chaieb L, Antal A, Walsh V, Paulus W (2008) Frequencydependent electrical stimulation of the visual cortex. Curr Biol 18:18391843. CrossRef Medline

Kawaguchi Y (1993) Groupings of nonpyramidal and pyramidal cells with specific physiological and morphological characteristics in rat frontal cortex. J Neurophysiol 69:416-431. Medline

Kawaguchi Y (1995) Physiological subgroups of nonpyramidal cells with specific morphological characteristics in layer II/III of rat frontal cortex. J Neurosci 15:2638-2655. Medline

Kelsom C, Lu W (2013) Development and specification of GABAergic cortical interneurons. Cell Biosci 3:19. CrossRef Medline

Khatoun A, Mc Laughlin M (2017) Improving the strength and focality of transcranial alternating current stimulation for clinical applications: a modelling study exploring the benefits of a subcutaneous electrode. Second International Brain Stimulation Conference, Barcelona, Spain.

König P, Engel AK, Singer W (1996) Coincidence detection or temporal integration: the role of the cortical neuron revisited. Trends Neurosci 19:130-137. CrossRef Medline

Krause B, Márquez-Ruiz J, Cohen Kadosh R (2013) The effect of transcranial direct current stimulation: a role for cortical excitation/inhibition balance? Front Hum Neurosci 7:602. CrossRef Medline

Markram H, Toledo-Rodriguez M, Wang Y, Gupta A, Silberberg G, Wu C (2004) Interneurons of the neocortical inhibitory system. Nat Rev Neurosci 5:793-807. CrossRef Medline

Marshall L, Helgadóttir H, Mölle M, Born J (2006) Boosting slow oscillations during sleep potentiates memory. Nature 444:610-613. CrossRef Medline

McIntyre CC, Grill WM, Sherman DL, Thakor NV (2004) Cellular effects of deep brain stimulation: model-based analysis of activation and inhibition cellular effects of deep brain stimulation: model-based analysis of activation and inhibition. J Neurophysiol 91:1457-1469. CrossRef Medline

Moro E, Schwalb JM, Piboolnurak P, Poon YY, Hamani C, Hung SW, Arenovich T, Lang AE, Chen R, Lozano AM (2011) Unilateral subdural motor cortex stimulation improves essential tremor but not Parkinson's disease. Brain 134:2096-2105. CrossRef Medline

Nguyen JP, Lefaucheur JP, Decq P, Uchiyama T, Carpentier A, Fontaine D, Brugières P, Pollin B, Fève A, Rostaing S, Cesaro P, Keravel Y (1999) Chronic motor cortex stimulation in the treatment of central and neuropathic pain: correlations between clinical, electrophysiological and anatomical data. Pain 82:245-251. CrossRef Medline

Nowak LG, Bullier J (1998) Axons, but not cell bodies, are activated by electrical stimulation in cortical gray matter: I. Evidence from chronaxie measurements. Exp Brain Res 118:477-488. CrossRef Medline

Nunez PL, Srinivasan R (2006) Electric fields of the brain: the neurophysics of EEG, Ed 2. New York: Oxford UP.

Nuti C, Peyron R, Garcia-Larrea L, Brunon J, Laurent B, Sindou M, Mertens P (2005) Motor cortex stimulation for refractory neuropathic pain: four year outcome and predictors of efficacy. Pain 118:43-52. CrossRef Medline

Opitz A, Falchier A, Yan CG, Yeagle EM, Linn GS, Megevand P, Thielscher A, Deborah AR, Milham MP, Mehta AD, Schroeder CE (2016) Spatiotemporal structure of intracranial electric fields induced by transcranial electric stimulation in humans and nonhuman primates. Sci Rep 6:31236. CrossRef Medline

Ozen S, Sirota A, Belluscio MA, Anastassiou CA, Stark E, Koch C, Buzsáki G (2010) Transcranial electric stimulation entrains cortical neuronal populations in rats. J Neurosci 30:11476-11485. CrossRef Medline

Pashut T, Wolfus S, Friedman A, Lavidor M, Bar-Gad I, Yeshurun Y, Korngreen A (2011) Mechanisms of magnetic stimulation of central nervous system neurons. PLoS Comput Biol 7:e1002022. CrossRef Medline

Picillo M, Moro E, Edwards M, Di Lazzaro V, Lozano AM, Fasano A (2015) Subdural continuous theta burst stimulation of the motor cortex in essential tremor. Brain Stimul 8:840-842. CrossRef Medline

Pogosyan A, Gaynor LD, Eusebio A, Brown P (2009) Boosting cortical activity at beta-band frequencies slows movement in humans. Curr Biol 19:1637-1641. CrossRef Medline

Povysheva NV, Gonzalez-Burgos G, Zaitsev AV, Kröner S, Barrionuevo G, Lewis DA, Krimer LS (2006) Properties of excitatory synaptic responses in fast-spiking interneurons and pyramidal cells from monkey and rat prefrontal cortex. Cereb Cortex 16:541-552. CrossRef Medline 
Priori A, Lefaucheur JP (2007) Chronic epidural motor cortical stimulation for movement disorders. Lancet Neurol 6:279-286. CrossRef Medline

Raco V, Bauer R, Tharsan S, Gharabaghi A (2016) Combining TMS and tACS for closed-loop phase-dependent modulation of corticospinal excitability: a feasibility study. Front Cell Neurosci 10:143. CrossRef Medline

Radman T, Ramos RL, Brumberg JC, Bikson M (2009) Role of cortical cell type and morphology in sub- and suprathreshold uniform electric field stimulation. Brain Stimul 2:215-228, 228.e1-3. CrossRef Medline

Rampersad SM, Jansse AM, Lucka F, Aydin Ü, Lanfer B, Lew S, Wolters CH, Stegeman DF, Oostendorp TF (2014) Simulating transcranial direct current stimulation with a detailed anisotropic human head model simulating transcranial direct current stimulation with a detailed anisotropic human head model. IEEE Trans Neural Syst Rehabil Eng 22:441-452. CrossRef Medline

Reato D, Rahman A, Bikson M, Parra LC (2010) Low-intensity electrical stimulation affects network dynamics by modulating population rate and spike timing. J Neurosci 30:15067-15079. CrossRef Medline

Ruhnau P, Neuling T, Fuscá M, Herrmann CS, Demarchi G, Weisz N (2016) Eyes wide shut: transcranial alternating current stimulation drives alpha rhythm in a state dependent manner. Sci Rep 6:27138. CrossRef Medline

Soediono B (1989) The handbook of brain theory and neural networks. J Chem Inf Model 53:719-725.

Stein RB (1967) Some models of neuronal variability. Biophys J 7:37-68. CrossRef Medline

Tal D, Schwartz EL (1997) Computing with the leaky integrate-and-fire neuron: logarithmic computation and multiplication. Neural Comput 9:305-318. CrossRef Medline

Thomson AM (1997) Activity-dependent properties of synaptic transmission at two classes of connections made by rat neocortical pyramidal axons in vitro. J Physiol 502:131-147. CrossRef Medline

Tranchina D, Nicholson C (1986) A model for the polarization of neurons by extrinsically applied electric fields. Biophys J 50:1139-1156. CrossRef Medline

Tsubokawa T, Katayama Y, Yamamoto T, Hirayama T, Koyama S (1991)
Chronic motor cortex stimulation for the treatment of central pain. In: Advances in stereotactic and functional neurosurgery 9: Proceedings of the 9th Meeting of the European Society for Stereotactic and Functional Neurosurgery, Malaga 1990 (Hitchcock ER, Broggi G, Burzaco J, MartinRodriguez J, Meyerson BA, Tóth S, eds), pp 137-139. Vienna: Springer Vienna.

Tsubokawa T, Katayama Y, Yamamoto T, Hirayama T, Koyama S (1993) Chronic motor cortex stimulation in patients with thalamic pain. J Neurosurg 78:393-401. CrossRef Medline

Valdés-Hernández PA, Sumiyoshi A, Nonaka H, Haga R, Aubert-Vásquez E, Ogawa T, Iturria-Medina Y, Riera JJ, Kawashima R, Roche A, Medical S (2011) An in vivo MRI template set for morphometry, tissue segmentation, and fMRI localization in rats. Front Neuroinform 5:26. CrossRef Medline

Vanneste S, Fregni F, De Ridder D (2013) Head-to-head comparison of transcranial random noise stimulation, transcranial AC stimulation, and transcranial DC stimulation for tinnitus. Front Psychiatry 4:158. CrossRef Medline

Vogels TP, Froemke RC, Doyon N, Gilson M, Haas JS, Liu R, Maffei A, Miller P, Wierenga CJ, Woodin MA, Zenke F, Sprekeler H (2013) Inhibitory synaptic plasticity: spike timing-dependence and putative network function. Front Neural Circuits 7:119. CrossRef Medline

Wang Y, Gupta A, Toledo-Rodriguez M, Wu CZ, Markram H (2002) Anatomical, physiological, molecular and circuit properties of nest basket cells in the developing somatosensory cortex. Cereb Cortex 12:395-410. CrossRef Medline

Wiethoff S, Hamada M, Rothwell JC (2014) Variability in response to transcranial direct current stimulation of the motor cortex. Brain Stimul 7:468-475. CrossRef Medline

Ziemann U (2004) TMS and drugs. Clin Neurophysiol 115:1717-1729. CrossRef Medline

Ziemann U, Rothwell JC, Ridding MC (1996) Interaction between intracortical inhibition and facilitation in human motor cortex. J Physiol 496: 873-881. CrossRef Medline 